RICARDO CARNEIRO AMARANTE

\title{
EFICÁCIA E SEGURANÇA DA TÉCNICA DO DESVIO MECÂNICO NA PREVENÇÃO DO AQUECIMENTO DO ESÔFAGO NA ABLAÇÃO DA FIBRILAÇÃO ATRIAL COM CATETER POR RADIOFREQUÊNCIA
}

Tese apresentada ao Instituto Dante Pazzanese de Cardiologia entidade associada da Universidade de São Paulo, para obtenção do título de doutor em Ciências

Programa de: Medicina, Tecnologia e Intervenção em Cardiologia 
RICARDO CARNEIRO AMARANTE

\title{
EFICÁCIA E SEGURANÇA DA TÉCNICA DO DESVIO MECÂNICO NA PREVENÇÃO DO AQUECIMENTO DO ESÔFAGO NA ABLAÇÃO DA FIBRILAÇÃO ATRIAL COM CATETER POR RADIOFREQUÊNCIA
}

\author{
Tese apresentada ao Instituto \\ Dante Pazzanese de Cardiologia - \\ Entidade associada da Universidade \\ de São Paulo, para obtenção do \\ título de doutor em Ciências \\ Programa de: Medicina, Tecnologia e \\ Intervenção em Cardiologia
}

Orientador: Prof. Dr. José Carlos Pachón Mateos

SÃO PAULO 


\section{Dados Internacionais de Catalogação na Publicação (CIP)}

Preparada pela Biblioteca do Instituto Dante Pazzanese de Cardiologia

Creprodução autorizada pelo autor

Amarante, Ricardo Carneiro

Eficácia e segurança da técnica do desvio mecânico na prevenção do aquecimento do esôfago na ablação da fibrilação atrial com cateter por radiofrequência / Ricardo Carneiro Amarante. -- São Paulo, 2019.

Tese(doutorado)--Instituto Dante Pazzanese de Cardiologia Universidade de São Paulo

Área de Concentração: Medicina, Tecnologia e Intervenção em

Cardiologia

Orientador: Prof. Dr. José Carlos Pachón Mateos

Descritores: 1. Ablação por Cateter de Radiofrequência. 2. Técnicas de Ablação. 3. Fibrilação Atrial 4. Arritmias Cardíacas.

USP/IDPC/Biblioteca/088/18 


\section{Dedicatória}

Aos meus pais, que sempre me apoiaram e são a minha maior fonte de incentivo na busca pelo crescimento e conhecimento.

Ao meu sobrinho, Lucas, pela melhor forma de amizade que pode existir.

Ao meu padrinho, Sérgio, que apesar de não estar fisicamente junto de nós, a sua presença em nossos corações nos fortalece e nos encoraja. 
"Todo homem toma os limites de seu próprio campo de visão como os limites do mundo." Schopenhauer, Arthur 


\section{Agradecimentos}

Ao grupo de arritmia do SEMAP que se tornou uma grande família. Agradeço a todos vocês pela amizade, aprendizado e tamanho apoio desde o início da nossa caminhada.

À minha professora, Laura Dias, pelo seu apoio e compartilhamento de tantos saberes.

Aos amigos que sempre estiveram presentes e deram suporte para que este trabalho fosse adiante.

Ao amigo, Dr. Jair, que desde o início da residência de clínica médica, sempre me aconselhou a tomar as melhores decisões e, assim, poder chegar até aqui.

Em especial, ao Dr. Enrique Pachón, pela sua amizade, competência e sabedoria que é compartilhada conosco diariamente. A sua participação foi fundamental para a concretização desta tese.

Ao meu orientador, Prof. Dr. Pachón, pelo seu apoio incondicional, por ser uma grande fonte de inspiração e de exemplo a ser seguido, pessoalmente e profissionalmente.

À Deus. 


\section{Normalização}

Esta tese está de acordo com as seguintes normas, em vigor no momento desta apresentação:

Universidade de São Paulo. Sistema Integrado de Bibliotecas. Diretrizes para apresentação de Dissertações e Teses da USP - Parte IV (Vancouver); $3^{\text {a }}$ edição - São Paulo: 2016. Elaborado por Vânia Martins Bueno de Oliveira Funaro, Maria Cláudia Pestana, Maria Cristina Cavarette Dziabas, Eliana Maria Garcia, Maria Fátima dos Santos, Maria Marta Nascimento, Suely Campos Cardoso.

Abreviaturas dos títulos dos periódicos de acordo com List of Journals indexed in Index

Medicus. 
SUMÁRIO

LISTA DE ABREVIATURAS

LISTA DE FIGURAS

LISTA DE TABELAS

LISTA DE GRÁFICOS

LISTA DE FLUXOGRAMAS

RESUMO

SUMMARY

1.Introdução

1.1 O tratamento da FA através da ablação com cateter por radiofrequência e o esôfago..........1

1.2 A relação anatômica entre o esôfago e o átrio esquerdo. ............................................... 2

1.3 Fatores de risco para formação da fístula atrioesofágica...............................................6

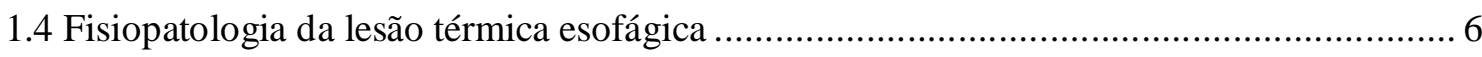

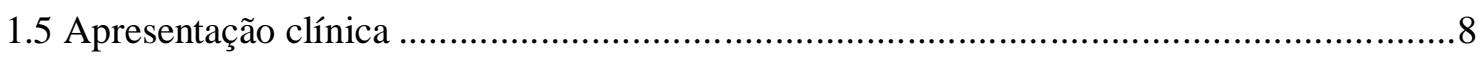

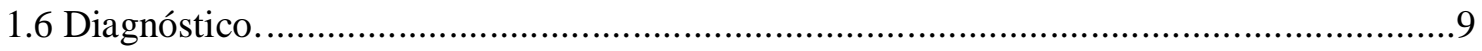

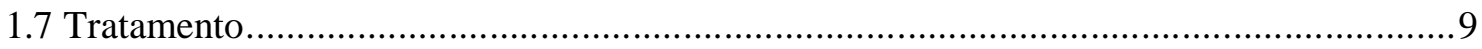

2. Técnicas de proteção do esôfago........................................................................11

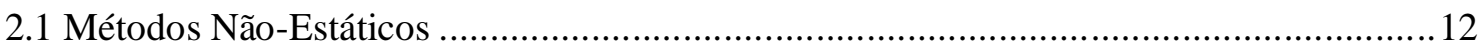

2.1.1 Visualização do lúmen esofágico por meio da fluoroscopia ..................................... 12

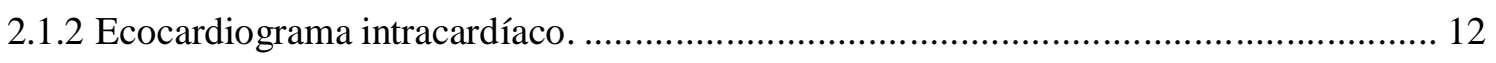

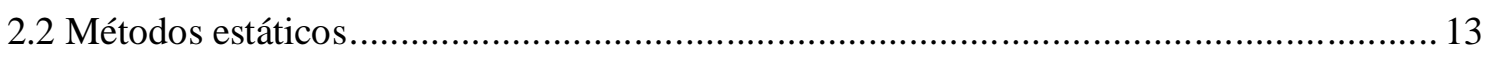

2.2.1 Sistemas de mapeamento eletroanatômico com fusão da imagem por ressonância nuclear

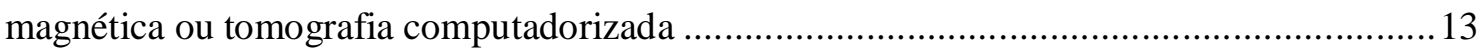

2.2.2 Utilização de dispositivos radiopacos para demarcar o trajeto do esôfago................... 14

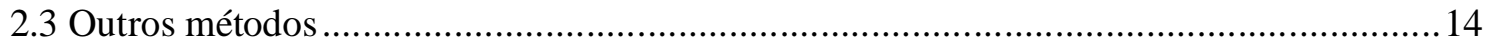

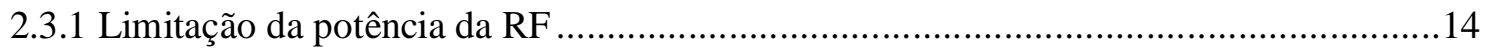

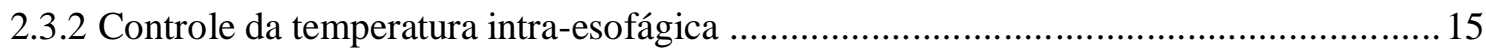

2.3.3 Refrigeração contínua do esôfago...................................................................... 17

2.3.4 Desvio mecânico do esôfago. .................................................................. 18

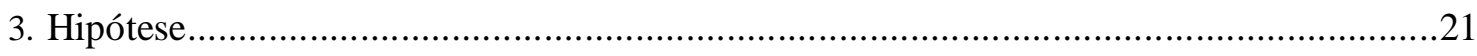

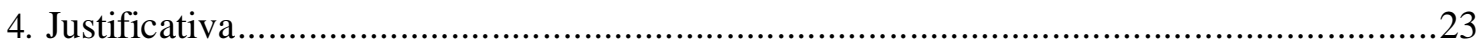

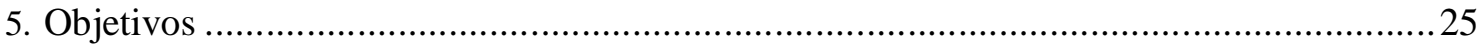

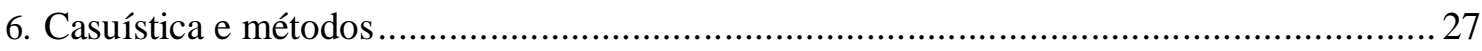




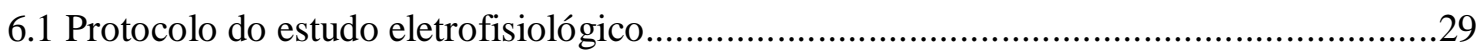

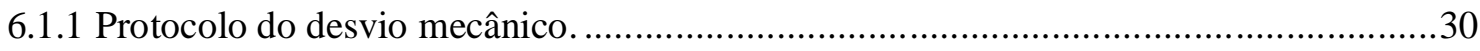

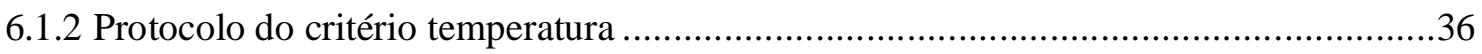

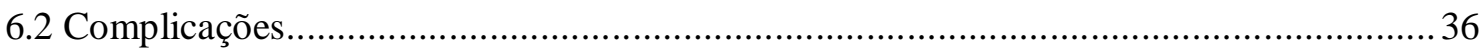

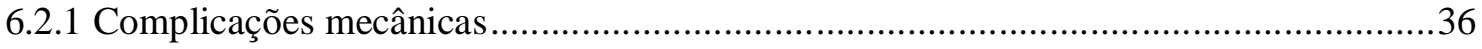

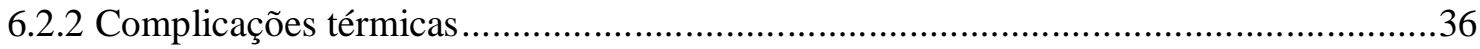

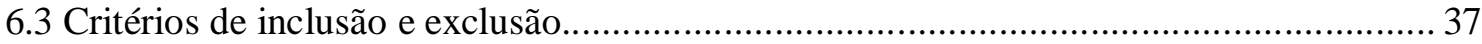

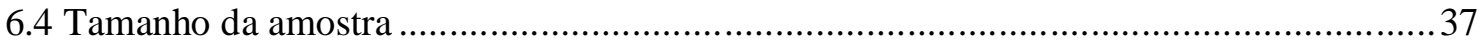

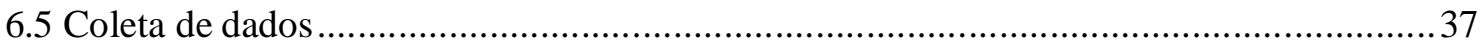

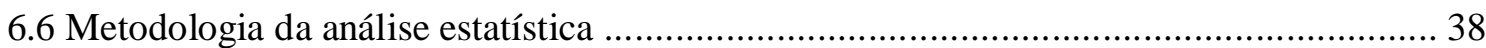

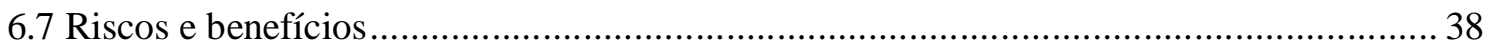

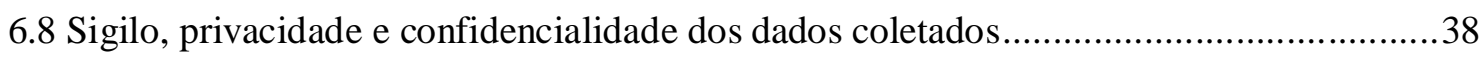

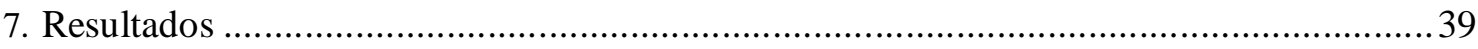

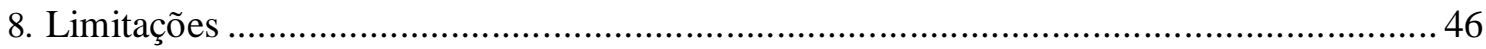

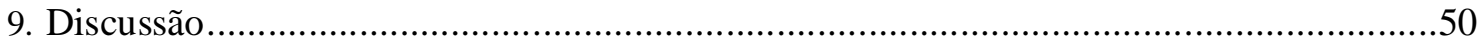

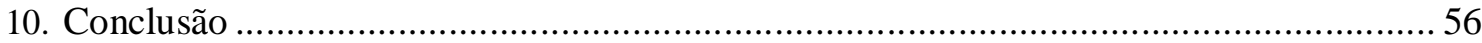

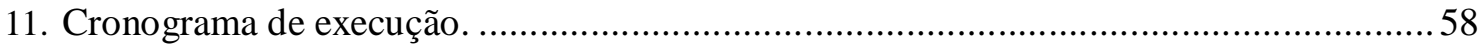

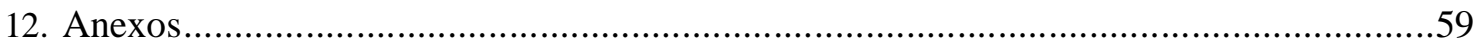

12.1. Apêndice A - Termo de Consentimento Livre e Esclarecido. .................................... 60

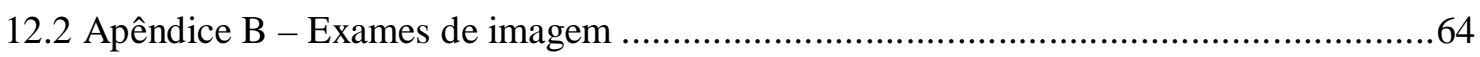

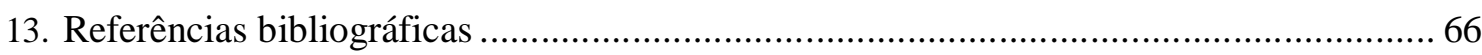


LISTA DE ABREVIATURAS 


\begin{tabular}{|c|c|}
\hline${ }^{\circ} \mathrm{C}$ & Graus Celsius \\
\hline $\mathrm{AE}$ & Átrio esquerdo \\
\hline AFA & Ablação da fibrilação atrial \\
\hline AVC & Acidente vascular cerebral \\
\hline $\mathrm{C}$ & Central \\
\hline CFAEs & Complex fractioned atrial electrograms \\
\hline $\mathrm{cm}$ & Centímetros \\
\hline DB & Distância basal \\
\hline $\mathrm{D}$ & Direita \\
\hline $\mathrm{DM}$ & Desvio mecânico \\
\hline EIC & Ecocardiograma intracardíaco \\
\hline EDA & Endoscopia digestiva alta \\
\hline $\mathrm{E}$ & Esquerda \\
\hline ETE & Ecocardiograma transesofágico \\
\hline tETE & Transdutor do ecocardiograma transtorácico \\
\hline FA & Fibrilação atrial \\
\hline FAE & Fístula atrioesofágica \\
\hline HCor & Hospital do Coração-SP \\
\hline IMC & Índice de massa corpórea $\left(\mathrm{Kg} / \mathrm{m}^{2}\right)$ \\
\hline OR & Odds ratio \\
\hline RF & Radiofrequência \\
\hline RNM & Ressonância nuclear magnética \\
\hline SEMAP & Serviço de Eletrofisiologia, Marca-passos e Arritmias Dr. Pachón \\
\hline TBK & Taquicardia de background \\
\hline tETE & Transdutor do ecocardiograma transesofágico \\
\hline TIE & Temperatura intraluminal esofágica \\
\hline TC & Tomografia computadorizada \\
\hline VP & Veia pulmonar \\
\hline W & Watts \\
\hline
\end{tabular}


Figura 1. Anatomia do esôfago e AE .................................................................................... 3

Figura 2. A localização mais comum do esôfago............................................................

Figura 3. Posições do esôfago vistas pela RNM ............................................................... 4

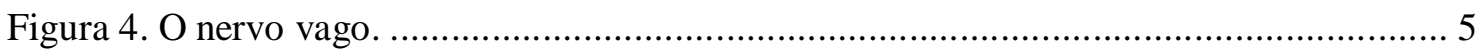

Figura 5. Cortes histológicos do esôfago e AE .............................................................. 5

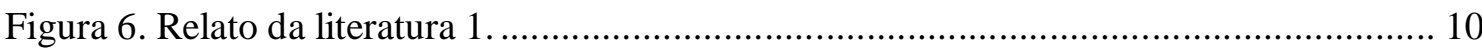

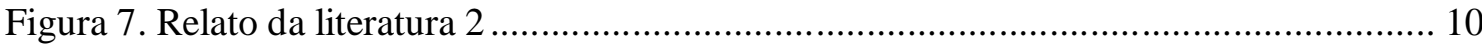

Figura 8. Composição do esôfago criado a partir do EIC ................................................... 13

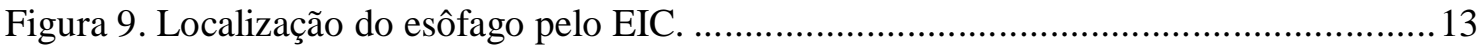

Figura 10. Sistema eletroanatômico 3D e fusão de imagens do AE e esôfago. ....................... 14

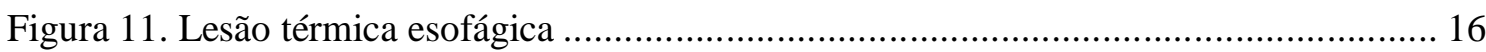

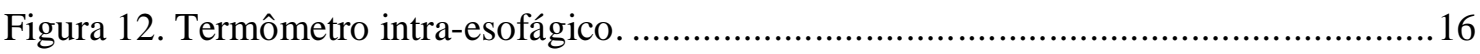

Figura 13. Termômetro SensiTherm........................................................................... 17

Figura 14. Sistema de refrigeração intra-esofágico. ...................................................... 18

Figura 15. Desvio mecânico do esôfago..................................................................... 19

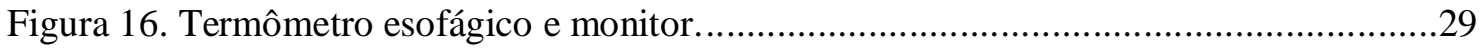

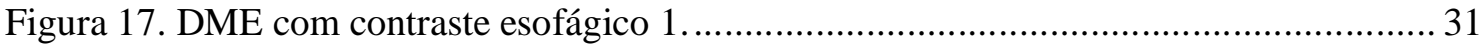

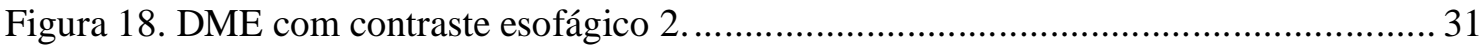

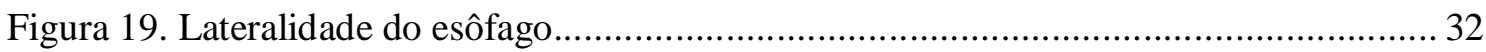

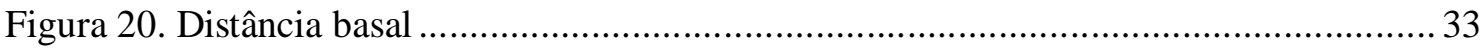

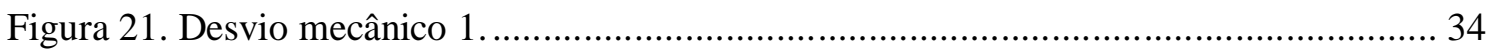

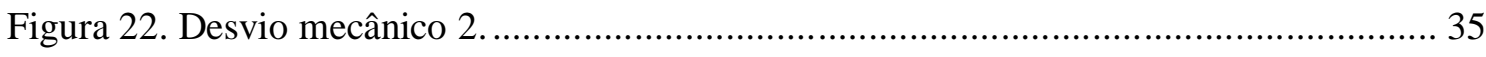

Figura 23. Ausência de elevação de temperatura após o DM ............................................ 35

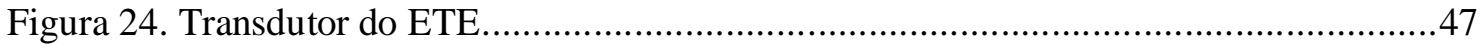

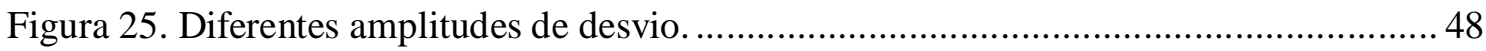

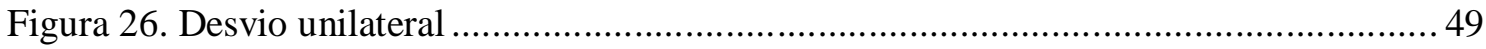




\section{LISTA DE TABELAS}


Tabela 1 - Características clínicas gerais dos pacientes n $(\%)$............................................. 40

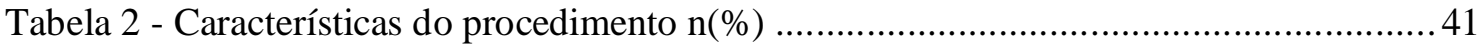

Tabela 3 - Análise por VP da TIE $\left({ }^{\circ} \mathrm{C}\right)$ pré e pós desvio mecânico ....................................... 43

Tabela 4 - Análise estatística da TIE $\left({ }^{\circ} \mathrm{C}\right)$ pré e pós desvio mecânico. ................................. 44

Tabela 5 - Análise da posição basal e amplitude pré e pós-desvio mecânico do esôfago ........45 
Gráfico 1 - Comportamento da temperatura de cada VP pré e pós-DME ............................44 
Fluxograma 1 - A dinâmica do protocolo da tese................................................................28 
RESUMO

AMARANTE, R.C. Eficácia e segurança da técnica do desvio mecânico na prevenção do aquecimento esofágico na ablação da fibrilação atrial com cateter por radiofrequência. São Paulo, 2019 69p, Tese - Instituto de Cardiologia Dante Pazzanese, Afiliado da Universidade de São Paulo.

Introdução: A fibrilação atrial é a taquiarritmia sustentada mais comum na prática clínica. Acomete cerca de $1 \%$ da população e aumenta sua prevalência com o avançar da idade, chegando a $12 \%$ das pessoas entre 75 e 84 anos. Aumenta a incidência de acidente vascular cerebral em cinco vezes e tipicamente estes eventos são mais graves que aqueles causados por outras etiologias. Está, também, associada ao aumento da incidência de insuficiência cardíaca, demência e mortalidade. Desta forma, grandes esforços são realizados há vários anos com o intuito de desenvolver métodos terapêuticos mais seguros e eficazes para esta patologia. Neste sentido, a ablação da fibrilação atrial (AFA) com cateter por radiofrequência vem se firmando como a opção mais eficaz para o tratamento definitivo desta arritmia. Entretanto, a aplicação da radiofrequência no antro das veias pulmonares e na parede posterior do átrio esquerdo pode gerar o aquecimento da parede esofágica e causar lesões térmicas extremamente graves e com alta mortalidade. A fisiopatologia destas lesões é baseada no aquecimento que ocorre das camadas mais externas para as mais internas, por vezes, suficientes para comprometer a irrigação vascular e os plexos vagais causando isquemia e alterações da motilidade esofágica. Nos casos mais graves podem ocorrer necrose, perfuração, mediastinite e fístula atrioesofágica. Estas lesões podem ser do tipo "detectáveis" através da endoscopia digestiva alta (erosões, úlceras e fístulas), quando acometem a mucosa, ou do tipo "não-detectáveis" (lesão do sistema vascular, dos plexos nervosos e da túnica muscular). Neste último caso, lesões recentes que ainda não progrediram até a mucosa ou lesões que podem se estabilizar nos planos mais externos da parede esofágica, ainda assim, com potencial de trazer sérias consequências, como a dismotilidade esofágica e gastroparesia.

Casuística e Método: Neste trabalho estudamos 55 pacientes (29\% do sexo feminino) submetidos a ablação de FA (AFA) por cateter de RF (80\% paroxística, $20 \%$ persistente) com monitoração da temperatura intraluminal do esofágica (TIE). Foi considerado sucesso aumentos relativos na TIE $<0,5^{\circ} \mathrm{C}$ ou na temperatura absoluta $<38,5^{\circ} \mathrm{C}$, com e sem deslocamento mecânico do esôfago (DM) realizado com o transdutor do ecocardiograma intra-esofágico. 
Resultados: Foi possível realizar a AFA sem DM e sem aquecimento $\geq 0,5^{\circ} \mathrm{C}$, em somente $8 / 55$ (15\%) dos casos. Em 47/55 (85\%) houve aquecimento, sendo necessário o DM. Em 41/47 (87\%) o DM foi capaz de evitar aumento da TIE $\geq 0,5^{\circ} \mathrm{C}$, porém, em $100 \%$ dos casos o DM foi capaz de prevenir aumento absoluto da $\mathrm{TIE} \geq 38,5^{\circ} \mathrm{C}$. Não ocorreram complicações térmicas. Conclusão: O DM mostrou-se seguro e altamente eficaz para prevenir o aumento de TIE sem aumentar a ocorrência de complicações e sem acrescentar custos à AFA.

Descritores: 1. Ablação por Cateter de Radiofrequência. 2. Técnicas de Ablação. 3. Fibrilação Atrial 4. Arritmias Cardíacas. 
SUMMARY

AMARANTE, R.C. Efficacy and safety of mechanical deviation technique in the prevention of esophageal heating in the ablation of atrial fibrillation with radiofrequency catheter. São Paulo, 2019 69p, Thesis - Institute of Cardiology Dante Pazzanese, Affliated of the University of São Paulo.

Introduction: Atrial fibrillation $(\mathrm{AF})$ is the most common sustained tachyarrhythmia in clinical practice. It affects about $1 \%$ of the population and increases its prevalence with advancing age, reaching $12 \%$ of people between 75 and 84 years. It increases the incidence of stroke in five times and typically these events are more serious than those caused by other etiologies. It is also associated with an increasing of heart failure, dementia, and mortality. Thus, great efforts have been made for several years to develop safer and more effective therapy for this pathology. In this sense, the ablation of AF with a radiofrequency (RF) catheter has been established as the most effective option for the definitive treatment of this arrhythmia. However, the application of RF in the antrum of the pulmonary veins and in the posterior wall of the left atrium can generate the heating of the esophageal wall that may cause extremely severe thermal lesions with high mortality. The pathophysiology of these lesions is based on the heating that occurs from the outer to the inner layers, sometimes enough to compromise the irrigation and the vagal plexus causing ischemia and esophageal motility abnormalities. In the most severe cases, necrosis, perforation, mediatinitis and atrioesophageal fistula may occur. These lesions may be "detectable" (erosions, ulcers and fistulae), or "non-detectable" through endoscopy (lesion of the vascular system, nerve plexuses and tunica muscularis). In the latter case, recent lesions that have not yet progressed to the mucosa or lesions that may stabilize in the outer planes of the esophageal wall can progress to severe lesions even if they are not early detectable.

Methods: In this study we evaluated 55 patients ( $29 \%$ female) who underwent AF ablation (AFA) by RF catheter ( $80 \%$ paroxysmal, $20 \%$ persistent) with intraluminal esophageal temperature monitoring (IET - relative increase $\geq 0,5^{\circ} \mathrm{C}$ or absolute temperature $\geq 38,5^{\circ} \mathrm{C}$ ), with and without mechanical esophageal displacement MED) performed with the intraesophageal echocardiographic transducer.

Results: It was possible to perform AFA without MED and without heating in only 8/55 (15\%) of the cases. In 47/55 (85\%) there was heating, and MED was required. In 41/47 (87\%) MED was able to avoid an increase in IET $\geq 0,5^{\circ} \mathrm{C}$, but in $100 \%$ of cases, the MED was able to prevent an absolute increase in IET $\geq 38,5^{\circ} \mathrm{C}$. There were no thermal complications. 
Conclusion: MED proved to be safe and highly effective in preventing an increase in LET without increasing the occurrence of complications and without adding costs to the AFA.

Descriptors: 1. Ablation by radiofrequency catheter. 2. Ablation techniques. 3. Atrial fibrillaton. 4. Cardiac arrhythmia. 


\section{Introdução}

A fibrilação atrial (FA) é uma arritmia supraventricular de fisiopatologia complexa e ampla. É caracterizada pela ativação atrial caótica que determina a perda da contração efetiva e implica em diversas consequências, tais como, a perda da atividade mecânica atrial durante o enchimento ventricular, queda do débito cardíaco, aumento da atividade simpática, remodelamento atrial elétrico, histológico e anatômico, taquicardiomiopatia e lentificação do fluxo sanguíneo atrial que favorece a formação de coágulos e aumento do risco de eventos cardioembólicos ${ }^{1}$. Tendo em vista as implicações elencadas, podemos entender a relevância desta arritmia em diversos contextos, como redução da qualidade de vida, da capacidade laboral, aumento da morbimortalidade, além dos custos, que podem ser gerados ao sistema de saúde em decorrência de suas diversas complicações.

A prevalência da FA também chama a atenção, por acometer cerca de $1 \%$ da população geral e até $12 \%$ dos indivíduos entre 75 e $84 \operatorname{anos}^{2}$. A taxa de acidente vascular cerebral (AVC) é cinco vezes maior ${ }^{3}$ e as complicações são mais graves em relação aos AVCs por outras etiologias $^{3,4}$. Além disso, há aumento em três vezes no risco de desenvolver insuficiência cardíaca $^{5}$, em duas vezes no risco de demência ${ }^{6}$ e dobra-se o risco de morte ${ }^{3}$. Estes argumentos justificam a necessidade de um tratamento rigoroso e eficaz. Neste contexto, a ablação por cateter através de radiofrequência vem sendo cada vez mais utilizada devido à evolução da técnica e à possibilidade da recuperação do ritmo sinusal.

\subsection{O tratamento da FA através da ablação com cateter por radiofrequência e o esôfago}

Nos últimos anos, diversas publicações têm demonstrado que a ablação da FA com cateter, por meio da radiofrequência (RF), está associada a melhor controle do ritmo ${ }^{7}$, melhora da qualidade de vida $^{7}$, melhora da função ventricular esquerda ${ }^{8,9,10}$, e até mesmo da mortalidade ${ }^{10}$.

Para que o procedimento seja realizado, é necessária a abordagem do átrio esquerdo (AE) por meio da punção transeptal ou através do forame oval patente, que irá permitir a passagem da(s) bainha(s), do cateter de mapeamento e de ablação. Nos casos de fibrilação atrial paroxística, a abordagem padrão na ablação da FA por RF baseia-se no mapeamento e isolamento elétrico das veias pulmonares $(\mathrm{VP})^{11}$ uma vez que o mecanismo deflagrador dessa arritmia se localiza, geralmente, nestas veias e no endocárdio adjacente ${ }^{12}$. 
$\mathrm{Na}$ abordagem da fibrilação atrial persistente, é recomendada a avaliação da parede posterior do AE com o objetivo de mapear e fazer ablação dos complex fractioned atrial electrograms (CFAEs) ${ }^{13}$, como também, realizar linhas de bloqueio adicionais ${ }^{14}$ quando necessário.

No Serviço de Eletrofisiologia, Marca-passos e Arritmias Dr. Pachón (SEMAP), Hospital do Coração (HCor), Hospital Sírio Libanês (HSL) e Complexo Hospitalar Edmundo Vasconcelos (CHEV), o procedimento de ablação da FA utiliza uma técnica estendida na qual, além do isolamento das VP, é realizado o mapeamento e ablação de substrato (ninhos de FA) ${ }^{15}$, confecção de linhas de bloqueio no septo interatrial direito e esquerdo, além do mapeamento e ablação da taquicardia de background (TBK) ${ }^{16}$ em busca de menores taxas derecorrência ${ }^{17}$.

Assim, seja na abordagem padrão como nas abordagens estendidas, existe grande risco de aquecimento e surgimento de lesão detectável ou não detectável no esôfago, sendo importante o rígido controle da temperatura intra-luminal esofágica (TIE), além da disponibilidade de métodos de proteção que permitam aplicar a RF mesmo nas regiões nas quais o AE apresenta-se superposto a este órgão.

$\mathrm{Na}$ ausência destes métodos de proteção, pode-se reduzir a potência ou o tempo de aplicação da RF, ou então, realizar isolamentos elétricos segmentares, interrompidos ou parciais nestas áreas. Mesmo com estes cuidados ainda há o risco de lesão térmica esofágica ${ }^{18,19}$ além de maior chance de recidiva da $\mathrm{FA}^{20}$ devido a ablações incompletas.

\subsection{A relação anatômica entre o esôfago e o átrio esquerdo}

O esôfago é um tubo fibromuscular que apresenta, aproximadamente, $25 \mathrm{~cm}$ de comprimento e $2 \mathrm{~cm}$ de diâmetro, sendo normalmente achatado ântero-posteriormente. Ele entra no mediastino superior entre a traqueia e a coluna vertebral, onde se situa anteriormente aos corpos vertebrais T1 à T4. Desce ao mediastino posterior num trajeto dorsal e à direita do arco aórtico e posterior ao pericárdio e ao AE (Figura 1). Neste ponto, verifica-se a menor distância entre o AE e o esôfago o qual avança num trajeto anterior e para a esquerda, passando finalmente através do hiato esofágico situado no diafragma ao nível da vértebra T10. 
Figura 1 - Anatomia do esôfago e AE.
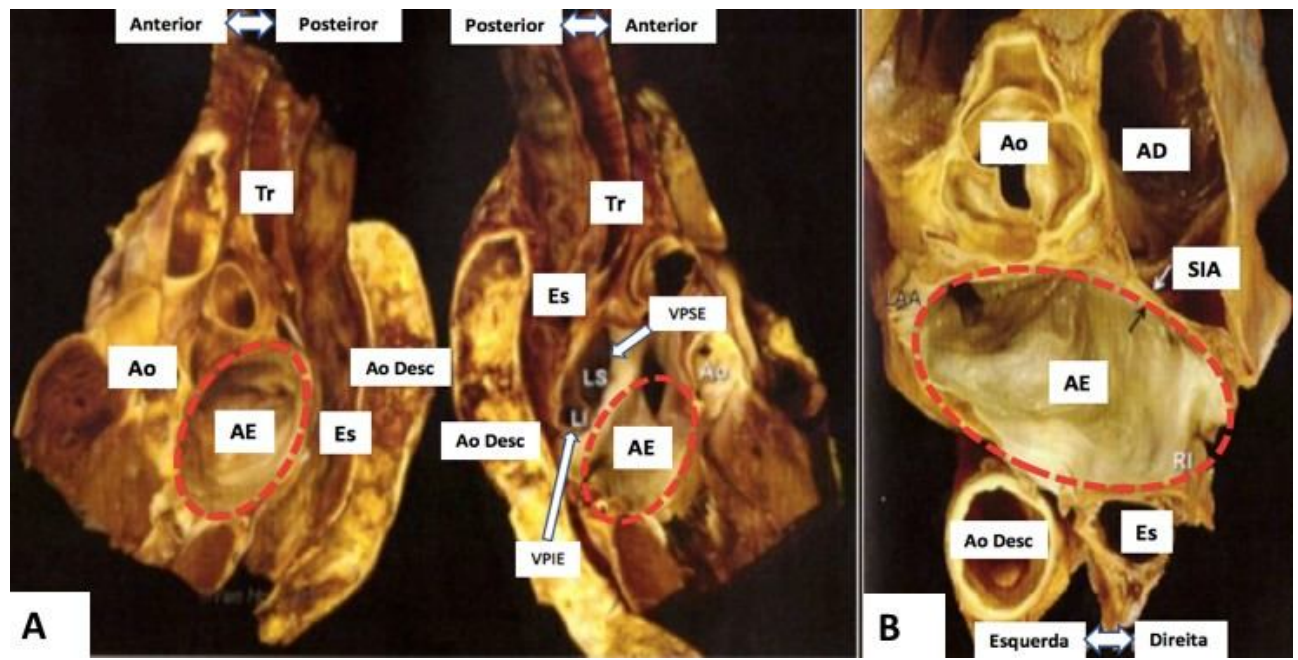

Ao: Aorta. AE: átrio esquerdo, Es: esôfago, Ao Desc: aorta descendente, Tr: traqueia, AD: átrio direito, Ant: anterior, Post: posterior ${ }^{21}$.

A posição anatômica do esôfago é muito variável entre indivíduos e, no mesmo paciente, muda frequentemente de um momento a outro devido à sua grande motilidade. Habitualmente, situa-se anteriormente à coluna vertebral e à direita da aorta torácica descendente ${ }^{22}$, de forma que, a localização próxima ao óstio das VPs esquerdas é mais frequente do que das VPs direitas $^{23,24}$. A avaliação anatômica pode ser realizada através de diversos métodos de imagem (Figura 2 e Figura 3). De acordo com Cury et al., o diâmetro transverso médio da área de contato do AE com o esôfago é de 18,9 \pm 4,4 mm, enquanto que a distância média entre as duas estruturas é de $1,9 \pm 0,7 \mathrm{~mm}^{25}$.

Figura 2 - A localização mais comum do esôfago.

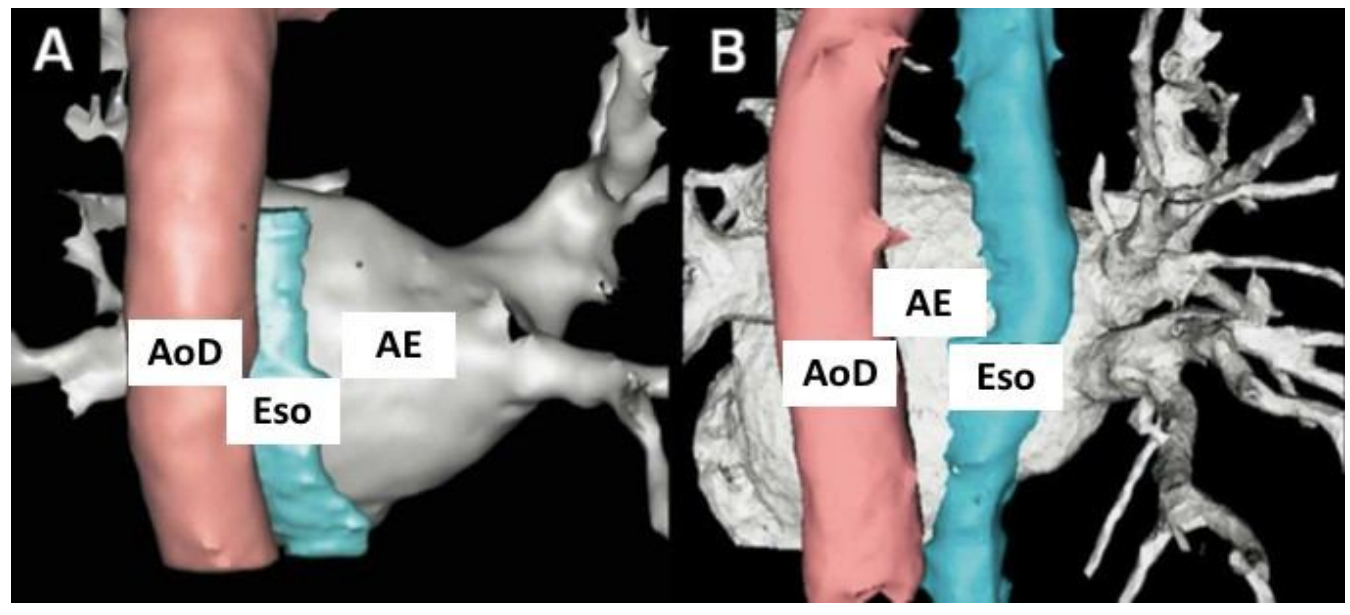

A) Usualmente, o esôfago está situado à esquerda no mediastino posterior e à direita e anterior da aorta descendente. B) Posição menos comum do esôfago, situado à direita no mediastino posterior e próximo às veias 
pulmonares direitas. Reconstrução anatômica utilizando tomografia computadorizada e sistema de mapeamento eletroanatômico 3D. Eso: esôfago. AoD: aorta descendente. AE: átrio esquerdo ${ }^{25}$

Figura 3 - Posições do esôfago vistas pela RNM.
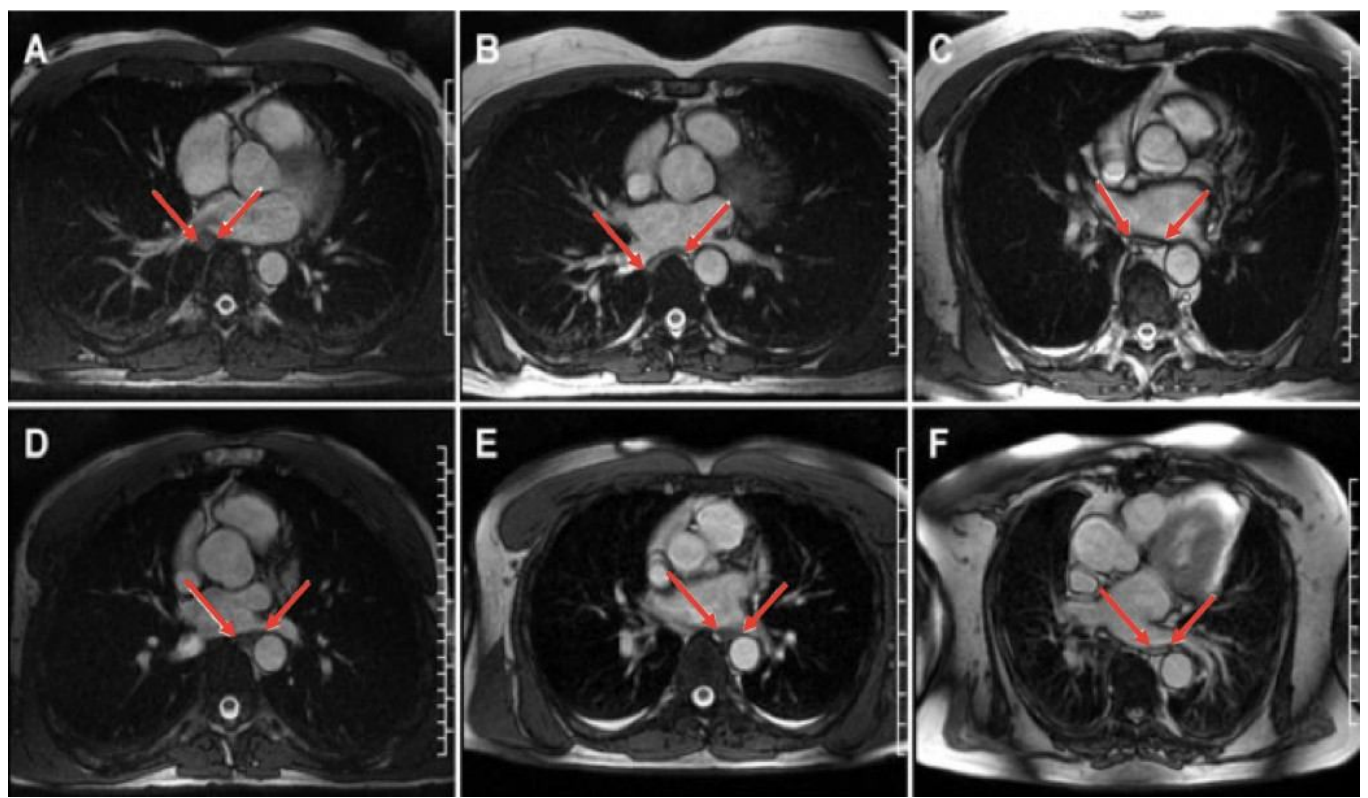

Exemplos de variações da relação entre o AE e esôfago. As setas indicam a localização e extensão látero-lateral do esôfago. A) O esôfago está lateral e à direita da coluna vertebral e muito próximo das veias pulmonares direitas. B) O esôfago está comprimido entre o átrio esquerdo e coluna vertebral, aproximando suas bordas laterais das veias pulmonares, direita e esquerda. C) Esôfago em contato com a parede posterior do átrio esquerdo. D) Esôfago localizado lateral e a esquerda do corpo vertebral, próximo ao óstio e antro das veias pulmonares esquerdas. E) Esôfago parcialmente comprimido pela aorta descendente, próximo ao óstio das veias pulmonares esquerdas. F) O esôfago é comprimido pela aorta descendente aproximando-o do antro e do óstio das veias pulmonares esquerdas ${ }^{26}$.

Do ponto de vista histológico, o esôfago segue o padrão de organização em quatro túnicas do tubo gastrointestinal. Deste modo, de dentro para fora, o esôfago é constituído pelas túnicas mucosa, submucosa, muscular e adventícia ${ }^{22}$.

A irrigação do terço superior do esôfago tem origem no ramo inferior da artéria tireóidea, do seu terço médio nos ramos da aorta torácica e do seu terço inferior nos ramos da artéria gástrica esquerda. Em relação à inervação (Figura 4), os plexos vagais e o tronco vagal esquerdo possuem trajeto anterior formando um extenso plexo que envolve a túnica adventícia deste órgão. 
Figura 4 - O nervo vago.

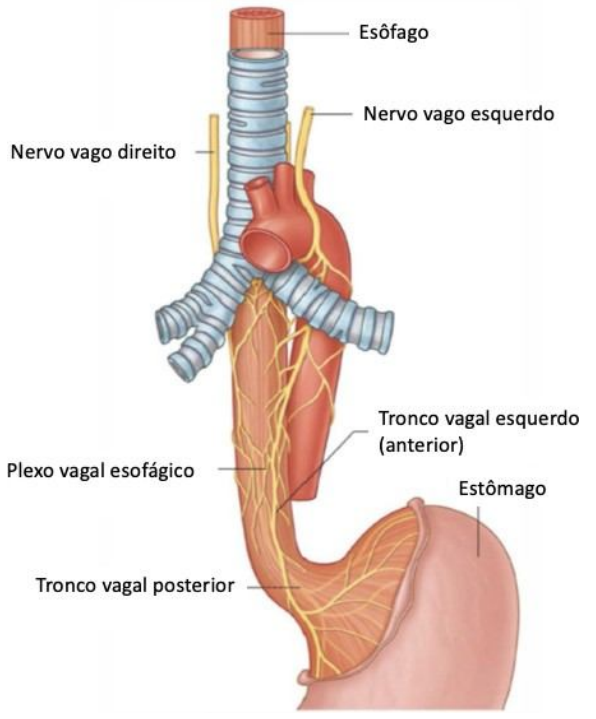

Distribuição da inervação do vago esquerdo e direito ${ }^{27}$.

Além de possuírem localização anterior, estes nervos estão localizados externamente ao pericárdio a uma distância de 2,5 a 6,5 mm tanto da parede posterior do AE como também da região antral das veias pulmonares ${ }^{28}$ (Figura 5).

Figura 5 - Cortes histológicos do esôfago e AE.

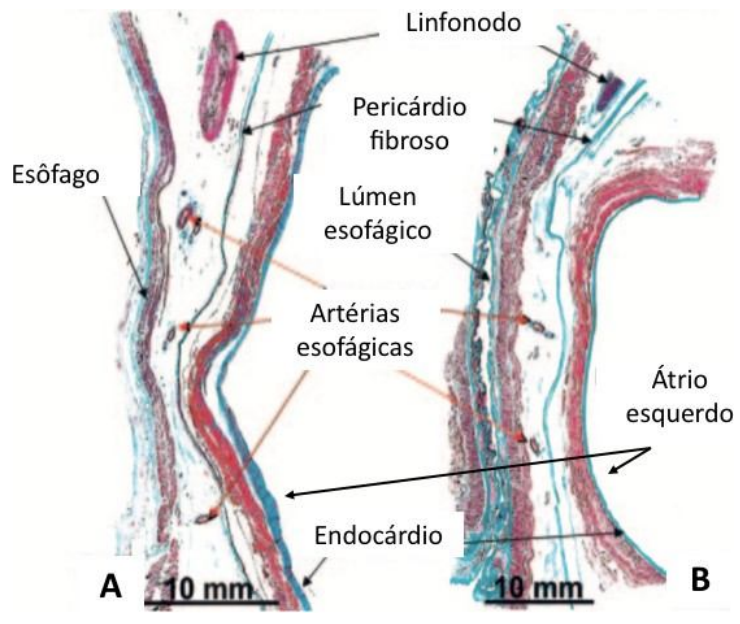

Em sequência, A e B, na mesma disposição. Demonstra-se a íntima relação entre o pericárdio fibroso, a parede posterior do $\mathrm{AE}$ e o esôfago, artérias esofágicas e tecido adiposo contendo linfonodos (corante tricomo de Masson) ${ }^{28}$. 
Assim, a ablação por RF na parede posterior do AE e nas VP apresenta o risco de ocasionar lesões térmicas na parede anterior do esôfago, detectáveis ou não por endoscopia convencional, e têm grande potencial de acometer tanto a irrigação arterial, como também, a inervação determinando lesões isquêmicas, infecção e alterações funcionais, como o refluxo gastroesofágico, que fortalece o conjunto de condições que contribuem para o agravo da lesão da parede esofágica. As lesões térmicas não detectáveis por endoscopia precoce, podem ocasionar disfunções por conta de alterações da inervação, da circulação ou da túnica muscular. Estas poderão evoluir futuramente para as camadas mais internas devido ao surgimento de isquemia, necrose, dismotilidade e refluxo gastroesofágico, que promove a queda do $\mathrm{pH}$ esofágico e permite o retorno da pepsina gástrica para o esôfago ${ }^{29,30}$.

\subsection{Fatores de risco para formação da fístula atrioesofágica}

São fatores de risco descritos para a formação da fístula atrioesofágica (FAE): presença de úlcera esofágica, AE com diâmetro aumentado, baixo índice de massa corpórea (IMC), extensa aplicação de RF ou sobreposição de linhas na parede posterior do AE, utilização de bainhas deflectíveis, utilização de cateteres de $8 \mathrm{~mm}$, tubos oro ou nasogástricos, anestesia geral, alta potência de RF aplicada na parede posterior do AE e, finalmente, aquecimento do esôfago com temperatura máxima luminal esofágica atingida ${ }^{29,31,32}$.

$\mathrm{Na}$ ausência de proteção específica, devido à relação anatômica próxima entre o esôfago e $\mathrm{AE}$, é adequado evitar ou reduzir as aplicações de RF nas áreas de grande proximidade ou de superposição destas estruturas $^{33}$. Como a fístula atrioesofágica (FAE) é pouco frequente, tornase difícil estabelecer relações de causa e efeito com significância estatística.

Em relação ao tipo de energia utilizada, é maior o número de casos de FAE com $\mathrm{RF}^{34}$, apesar de serem relatados casos com o uso da crioablação ${ }^{35}$, ultrassom ${ }^{36}$ e com a ablação cirúrgica $^{37}$. De modo geral, o número de ablações que utilizam a RF é maior do que aquelas que utilizam outros tipos de energia. Adicionalmente, um maior número de lesões térmicas esofágicas tem sido descrito nos casos realizados com navegação robótica quando comparado com a ablação por RF convencional utilizando parâmetros similares ${ }^{38}$.

\subsection{Fisiopatologia da lesão térmica esofágica}

Atualmente, é aceito que a formação da FAE depende da lesão térmica direta pela RF com o consequente comprometimento do suprimento sanguíneo arterial. Este mecanismo se dá 
através da oclusão de arteríolas terminais, associado a possíveis infecções do lúmen esofágico e pela lesão do plexo vagal anterior o qual compromete a contratilidade do antro gástrico e do esfíncter esofagiano inferior os quais irão determinar aumento do refluxo do conteúdo ácido gástrico $^{31,33,34}$. Naturalmente, numa fase precoce, estas lesões podem ser ou não detectáveis através de endoscopia.

De acordo com Kapur et al. ${ }^{34}$, tanto a parede posterior do AE como a parede anterior do esôfago podem ficar fragilizadas após a ablação por RF. Em decorrência da falta de relatos de necrose e perfuração atrial na ausência de lesão esofágica, enquanto que a lesão isolada do esôfago é bem reconhecida, deduz-se que a lesão primária parece ocorrer no esôfago (ulceração) e o processo de fistulização parece progredir em direção ao AE.

Pela primeira vez, em publicação recente ${ }^{39}$, foi demonstrada a correlação direta entre lesão térmica do esôfago pós-ablação detectada por EDA e perfuração esofágica. Dos 832(100\%) pacientes submetidos à ablação de FA, 18\%(150) apresentaram lesões térmicas visíveis. Do total, 12\%(98) dos pacientes evoluíram com esofagite (erosão) e 6\%(52) com úlceras. Dos pacientes que apresentaram esofagite (erosão), nenhum apresentou perfuração. No entanto, todos os 5 pacientes que apresentaram perfuração esofágica tiveram o diagnóstico prévio de úlcera na EDA. Estes 5 pacientes, correspondem a 10\% daqueles com o diagnóstico de úlcera no pós-procedimento. Assim, os autores consideram que lesão térmica seria um prérequisito para o desencadeamento da cascata de eventos que determinará o surgimento da FAE e que aumentos na TIE $>40,5^{\circ} \mathrm{C}$ estão associados ao aumento de 2,1 vezes no risco de lesões. Além disso, o refluxo gastroesofágico seria um fator crucial na inflamação da parede deste órgão, determinando menor resistência nas regiões onde houve a agressão térmica. Desta maneira, a úlcera esofágica de etiologia térmica seria uma lesão de alto risco para formaçãoda FAE e o risco de lesão térmica não pode ser descartado caso haja qualquer aumento da TIE.

Schmidt et al., realizaram endoscopia digestiva alta (EDA) em 28 pacientes 24 horas após o procedimento de ablação de FA. Identificaram que até $47 \%$ dos casos apresentavam alterações da parede esofágica, sendo que $29 \%$ apresentavam esofagite (erosão) e $18 \%$ úlceras decorrentes de lesão térmica ${ }^{40}$. Nesse estudo, apesar de não ter sido realizada EDA préprocedimento, o aspecto de lesão aguda, focal e localização na região anterior da parede do esôfago são indicativos de que seja pouco provável que pudessem ser lesões pré-existentes e não relacionadas ao procedimento de ablação.

Portanto, os pacientes que apresentam a suspeita ou o diagnóstico precoce de lesão térmica do esôfago pós-ablação, devem ter reavaliações mais frequentes e uma terapia medicamentosa rigorosa e mais potente com o propósito de minimizar os riscos de evolução 
para complicações maiores ${ }^{34}$. Não obstante, deve-se considerar que um número não definido de lesões térmicas não detectáveis por EDA precoce ocorre nestes procedimentos, podendo iniciar a cascata de complicações subsequentes.

\subsection{Apresentação clínica}

A FAE, apesar de ser uma complicação rara $(0,04$ a 0,25\%), possui elevada morbidade e altíssima mortalidade atingindo valores superiores a $80 \%^{34}, 41,42$. Representa a segunda causa de morte $(15,6 \%)$ como complicação do procedimento de ablação de FA, ficando atrás do tamponamento cardíaco apenas ${ }^{41}$.

Geralmente, o diagnóstico da FAE é realizado entre 2 dias a 6 semanas após o procedimento. Sua apresentação inicial pode variar desde febre, disfagia, hematêmese ou melena, pericardite, derrame pericárdico e/ou pleural, sepse, embolia séptica ou gasosa, endocardite, convulsão e $\mathrm{AVC}^{43}$. Han et al., descreveram que os pacientes com FAE costumam apresentar o quadro inicial com febre em $73 \%$ dos casos, sintomas neurológicos (déficits focais, convulsão, confusão mental e perda de consciência) em $72 \%$, sintomas gastrointestinais (hematêmese, melena, disfagia, odinofagia, náuseas e vômitos) em $41 \%$ e cardíacos (dor torácica, dispnéia e palpitações) em 40\%. Com relação aos preditores de mortalidade pela análise multivariada, a presença de sintomas neurológicos apresentou um odds ratio (OR): 16, $\mathrm{p}<0,001$, enquanto que a presença de sangramento digestivo, OR: 4,22, $\mathrm{p}<0,047^{44}$.

A gastroparesia é outra complicação decorrente da lesão térmica dos plexos vagais do esôfago e pode não ser acompanhada de lesões detectáveis da mucosa. Caracteriza-se por sintomas de obstrução gástrica na ausência de um componente mecânico. Os sintomas podem ter início após 3 horas a 3 semanas após a ablação. O mecanismo ocorre por lesão dos plexos vagais, que possuem trajetória ao longo da parede anterior do esôfago, os quais têm papel importante na contratilidade gástrica, do antro e do piloro ${ }^{29,45}$. Por esta relação anatômica muito próxima, o nervo vago e seus plexos podem ser lesados durante o procedimento de ablação de FA e devem ser igualmente protegidos, independente das lesões da mucosa. 


\subsection{Diagnóstico}

Quando há suspeita diagnóstica de FAE, um hemograma deve ser solicitado, pois, leucocitose é um marcador sensível da sua presença. A hemocultura de pacientes com sepse relacionada à FAE geralmente apresenta crescimento de bactérias Gram-positivas ${ }^{34}$.

No entanto, o método diagnóstico de escolha deve ser a tomografia computadorizada (TC) de tórax ou ressonância nuclear magnética (RNM) com contraste intravenoso. A fase inicial do exame pode identificar a presença de pneumomediastino ou pneumopericárdio. A fase contrastada poderá demonstrar o extravasamento de contraste entre AE e esôfago ou mediastino, confirmando a presença do trajeto fistuloso. É recomendável a utilização de meio de contraste por via oral para poder auxiliar no diagnóstico de ruptura esofágica isolada ${ }^{33,34}$. Procedimentos que envolvem a manipulação do esôfago, como a EDA, devem ser evitados a fim de reduzir o risco de embolização aérea maciça devido a insuflação do esôfago.

Já a investigação e confirmação diagnóstica da gastroparesia se dá por meio de métodos que comprovam o retardo no esvaziamento gástrico, como por exemplo, cintilografia com alimentos marcados com radioisótopo ou RNM para avaliar o esvaziamento gástrico ${ }^{45,46}$ já que a EDA pode ser totalmente inconclusiva nesta fase.

\subsection{Tratamento}

Na prática clínica são amplamente utilizados os inibidores da bomba de prótons, inibidores H2 e sucralfato, sendo prescritos alguns dias antes até 4 a 6 semanas após o procedimento de ablação, principalmente, nos casos onde é identificada a lesão da mucosa esofágica ${ }^{33,34}$, ou mesmo o seu aquecimento.

Uma vez que o diagnóstico de lesão esofágica é estabelecido, o tratamento deve ser realizado precocemente, podendo ser utilizada a técnica com stent por via endoscópica ou, preferencialmente, por técnica cirúrgica ${ }^{43,47,48}$ (Figura 6 e Figura 7). No entanto, a análise de uma coorte retrospectiva com 29 pacientes que apresentaram FAE após procedimento de ablação de FA, evidenciou que $100 \%$ dos pacientes que foram tratados com stent por via endoscópica morreram, enquanto que $59 \%$ dos pacientes que foram submetidos ao procedimento cirúrgico sobreviveram. Já a mortalidade sem qualquer tratamento foi de $100 \%{ }^{49}$.

Em caso de gastroparesia, dependendo do grau de lesão, o tratamento pode ser realizado através de modificação dietética, suporte nutricional, procinéticos, injeção de toxina botulínica intra-pilórica e, até mesmo, através de estimulação elétrica gástrica. Pesquisas apontam que, geralmente, há resolução em semanas ${ }^{45}$. 
Quanto ao amplo espectro de sinais e sintomas decorrentes da lesão esofágica, a orientação do paciente deve ser muito bem esclarecida antes da alta hospitalar para poder antecipar ao máximo o diagnóstico de possíveis complicações.

Figura 6 - "Relato da literatura 1".
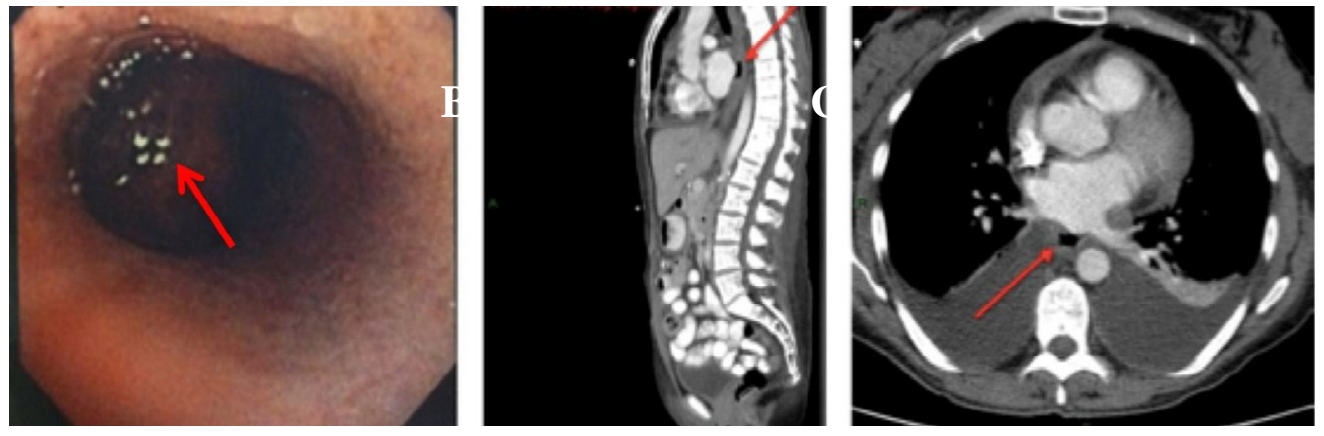

Paciente de 50 anos de idade que foi submetido a ablação de FA com cateter por RF. Quatro semanas após, apresentou hematêmese e foi submetido a EDA que identificou a presença de trombo na parede anterior do esôfago (A). A TC de tórax demonstrou a presença de derrame pleural e contorno atrial anormal, sugestivo de fístula atrioesofágica (B e C). Foi realizado procedimento cirúrgico com colocação de patch no AE, ressecção da úlcera e anastomose do esôfago ${ }^{50}$. Devemos levar em consideração que a realização de EDA em pacientes com suspeita de FAE está contra-indicada por riscos de complicações.

Figura 7 - "Relato da literatura 2".
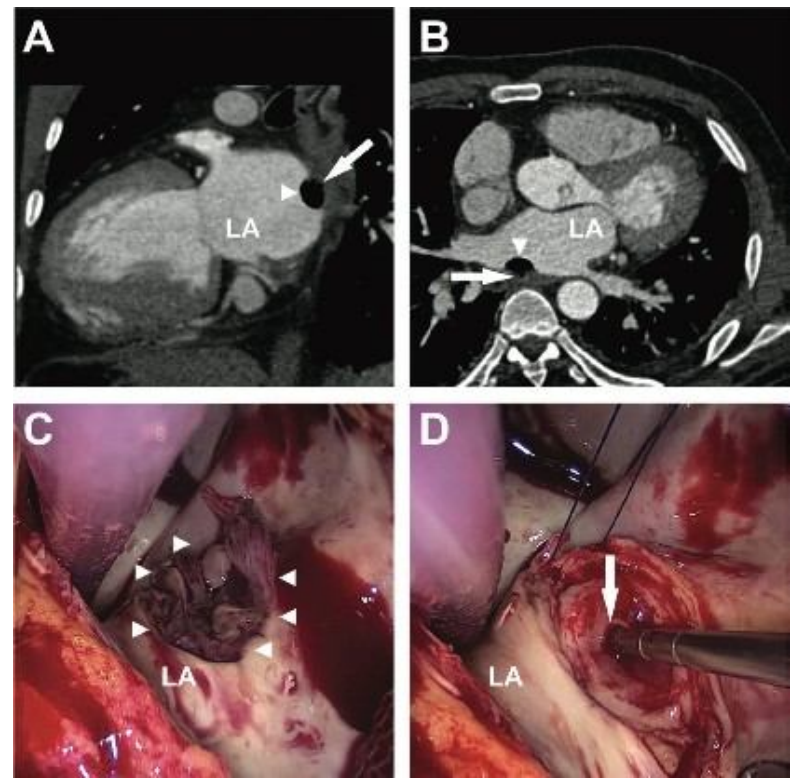

Paciente do sexo masculino, 45 anos, foi submetido a ablação de FA com cateter por RF. Dias após, apresentou quadro febril, hemiparesia e hemiparestesia à direita. Negava queixas gastrointestinais e dor torácica. 
Apresentava leucocitose, aumento de troponina $\mathrm{T}$ e eletrocardiograma normal. A TC de tórax, demonstrou a presença de fístula atrioesofágica (A e B). O paciente foi submetido a cirurgia cardíaca, sendo identificada perfuração de $1,5 \mathrm{~cm}$ na parede posterior do $\mathrm{AE}$, próximo a veia pulmonar inferior direita $(\mathrm{C}, \mathrm{D})$. $\mathrm{O}$ reparo do $\mathrm{AE}$ foi realizado com patch de pericárdio bovino, enquanto que a fístula do esôfago foi corrigida por sutura ${ }^{51}$.

\section{Técnicas de proteção do esôfago}

Diante de tais complicações, diversas técnicas foram desenvolvidas para proteção do esôfago oferecendo maior segurança durante a aplicação da RF nas VP e na parede posterior do AE. Qualquer estratégia utilizada para limitar ou evitar a aplicação de RF nas regiões próximas ao esôfago dependem de informações acuradas a respeito da localização deste órgão em relação as áreas-alvo. A dificuldade se dá pela grande variação anatômica, de trajetos e pela mobilidade constante deste órgão.

Como ainda não está definido se há um valor seguro de potência de RF que possa ser liberada próximo ao esôfago ${ }^{19}$, o método adequado para evitar lesões térmicas seria a não aplicação de energia nestas regiões. No entanto, como frequentemente há sobreposição entre as $\mathrm{VP}$, parede posterior do AE e esôfago ${ }^{25}$, este método pode resultar em ablações incompleta por impedir que toda a energia de RF necessária seja aplicada num determinado ponto e, com isso, haver o comprometimento do resultado final do procedimento e maior taxa de recidivas ${ }^{20}$.

Tendo em vista que o esôfago tem movimentação constante, os métodos de aquisição de imagem realizados no início do procedimento podem ser falhos caso não sejam capazes de atualizar a posição do esôfago em tempo real. Em conformidade, Starek et al., analisaram a posição basal do esôfago pré-procedimento por tomografia e compararam com a sua posição no início do procedimento, agora, por radiografia rotacional 3D do esôfago. Foi demonstrado que em apenas $35,7 \%$ dos casos havia concordância na posição do esôfago ${ }^{52}$. Já Daoud et al., observaram modificação de até $50 \%$ no diâmetro do esôfago num total de $44 \%$ de pacientes que foram submetidos a ablação de $\mathrm{FA}^{53}$. Por fim, Good et al., demonstraram que $67 \%$ dos pacientes submetidos a ablação de FA sob sedação profunda e administração de meio de contraste com bário, apresentaram deslocamento lateral do esôfago $\geq 2 \mathrm{~cm}$ e $4 \%$ tiveram um deslocamento $\geq 4 \mathrm{~cm}^{54}$.

Os métodos de localização do esôfago serão divididos em dois grupos: não-estáticos (atualizam a posição do esôfago em tempo real) e estáticos (não atualizam a posição do esôfago em tempo real). 


\subsection{Métodos Não-Estáticos}

\subsubsection{Visualização do lúmen esofágico por meio da fluoroscopia}

Como o esôfago é um órgão móvel no mediastino e apresenta movimentosperistálticos frequentes, ele pode modificar a sua posição em relação ao AE durante o procedimento de ablação $^{52,54}$. A administração de meio de contraste baritado $(20-30 \mathrm{ml})$ permite que o mesmo fique aderido à mucosa esofágica por 30 a 60 minutos $^{55}$. Assim, através da fluoroscopia, é possível visualizar a posição do esôfago em tempo real.

Um ponto questionável sobre esta técnica é que não é possível definir com precisão a espessura da borda do esôfago porque, nesta situação, visualizamos apenas o seu lúmen. No entanto, segundo Daoud et al., não houve diferenças significativas entre o diâmetro esofágico avaliado pelo esofagograma baritado e tomografia computadorizada ${ }^{53}$. Apesar da visualização em tempo real do trajeto esofágico, esta técnica ainda registra lesões térmicas relacionadas ao esôfago ${ }^{32}$.

\subsubsection{Ecocardiograma intracardíaco}

O ecocardiograma intracardíaco (EIC) permite a avaliação em tempo real da posição do esôfago em relação ao $\mathrm{AE}$, a delimitação das suas bordas, como também, a integração da imagem com o sistema de mapeamento eletroanatômico 3D (figura 8 e figura 9) e tem a vantagem de não utilizar fluoroscopia para a localização. Dentre outras características, as imagens do ecocardiograma permitem a avaliação das regiões do esôfago em contato com a parede posterior do AE e da distância entre estas duas estruturas. Desta forma, podem-se evitar aplicações de RF nas regiões próximas ao esôfago e observar o padrão de formação das microbolhas, que podem indicar aquecimentos excessivos do endocárdio atrial. Pode ser utilizado, também, para avaliar a presença de trombos intra-cavitários, auxiliar na punção transeptal e na avaliação do espaço pericárdico ${ }^{56}$. No entanto, o EIC não é capaz de modificar a posição do esôfago em caso de sobreposição a uma área-alvo para ablação. 
Figura 8 - Composição do esôfago criado a partir do EIC.

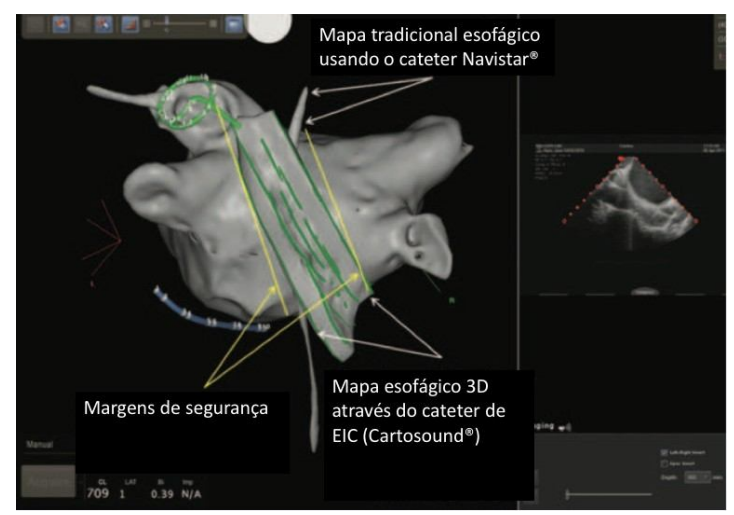

EIC integrado com o sistema eletroanatômico 3D - Carto 3. Também, foi criado o modelo do AE com suas respectivas veias pulmonares. Nas regiões adjacentes aos limites das bordas do esôfago, evitam-se aplicações de $\mathrm{RF}^{56}$.

Figura 9 - Localização do esôfago pelo EIC.

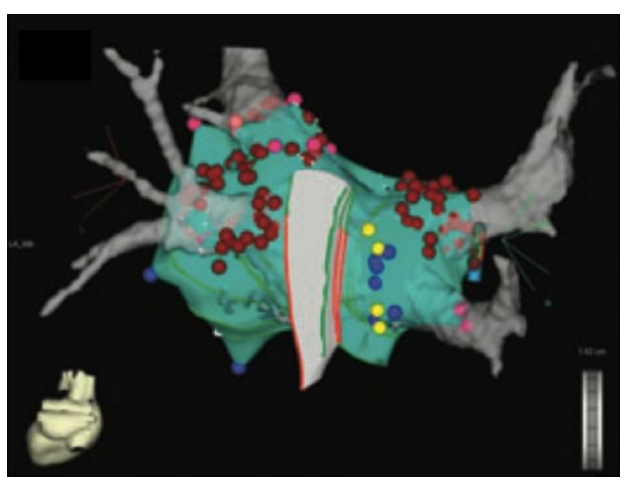

Superposição de imagens geradas pelo EIC (Carto-Sound ${ }^{\mathrm{TM}}$ ) e RNM, mostrando a relação do esôfago (cinza), com o $\mathrm{AE}$ (verde). Visão posterior ${ }^{26}$.

\subsection{Métodos Estáticos}

\subsubsection{Sistemas de mapeamento eletroanatômico com fusão da imagem por ressonância} nuclear magnética ou tomografia computadorizada.

A utilização da tomografia computadorizada (TC) ou da ressonância nuclear magnética (RNM) pré-procedimento permite que sejam gerados os modelos do átrio esquerdo e esôfago e, posteriormente, estas imagens serão fundidas com a anatomia construída pelo sistema de mapeamento eletroanatômico 3D (Figura 10). A limitação deste sistema reside no fato de serem geradas imagens estáticas. Desta forma, modificações da posição do esôfago durante o 
procedimento não serão identificadas e, também, poderá ser criada uma falsa impressão de segurança durante a aplicação da $\mathrm{RF}^{52,57}$.

Figura 10 - Sistema eletroanatômico 3D e fusão de imagens do AE e esôfago.

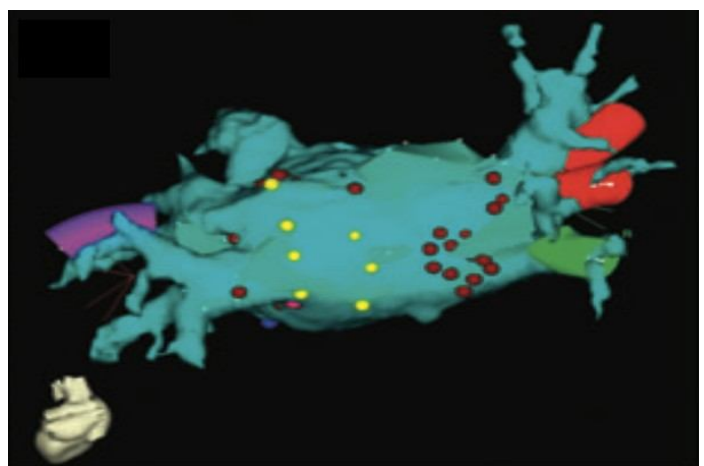

Através do sistema de mapeamento eletroanatômico 3D e fusão de imagens do AE e do esôfago, que foram geradas pela RNM, foi possível delimitar as bordas laterais do esôfago através da marcação de pontos de cor amarela ${ }^{26}$.

\subsubsection{Utilização de dispositivos radiopacos para demarcar o trajeto do esôfago.}

Esta técnica pode ser realizada através da utilização de um termômetro esofágico ou por meio do uso de cateteres de eletrofisiologia os quais irão mostrar, de forma aproximada, o trajeto e bordas do esôfago.

Também é possível utilizar um sistema de mapeamento eletroanatômico 3D que possibilita demarcar com pontos as bordas laterais do esôfago. Através do posicionamento de um cateter na luz esofágica e, que seja reconhecido pelo sistema de mapeamento eletroanatômico, é possível delimitar o trajeto estático do esôfago ${ }^{26}$.

\subsection{Outros métodos}

\subsubsection{Limitação da potência da $\mathbf{R F}$}

A redução da energia aplicada na parede posterior do AE, com o intuito de reduzir o risco de lesões esofágicas térmicas é, provavelmente, a técnica mais utilizada. Alguns autores recomendam a redução da potência para $\leq 25 \mathrm{~W}$ e aplicações com duração $\leq 30$ segundos ${ }^{32,33}$. De acordo com Bahnson et al., seria razoável limitar a potência da RF em valores abaixo de 20W por 15 a 20 segundos em cada aplicação, quando próximo ao esôfago, e aguardar 180 
segundos no mínimo, para que haja o resfriamento do órgão e possam ser feitas novas aplicações. No entanto, ainda são necessários mais dados para fundamentar a segurança desta técnica ${ }^{19}$.

Assim, é fundamental saber a localização do esôfago com precisão para que sejam evitadas aplicações de RF em regiões próximas. A localização pode ser feita através do uso de contraste esofágico, ultrassonografia que permite identificar além do lúmen, as bordas do esôfago em tempo real, uso de termômetros esofágicos que alertam para variações de temperatura em consequência a liberação de RF em regiões próximas ao esôfago e, que também, permitem ter uma noção aproximada do trajeto deste órgão.

No entanto, quando utilizada de forma isolada, o grande desafio desta técnica está em saber qual é a quantidade de energia segura e, ao mesmo tempo, suficiente para obter uma ablação completa ${ }^{26}$. Esta técnica é geralmente associada ao uso de termômetro esofágico.

\subsubsection{Controle da temperatura intra-esofágica (TIE)}

O monitoramento da TIE em tempo real permite que as aplicações de RF sejam limitadas de acordo com o aumento da temperatura. No entanto, a literatura não é precisa quanto ao valor máximo que justifique a interrupção da aplicação da RF.

Assim, quando utilizados valores absolutos da TIE entre $38,5^{\circ} \mathrm{C}$ a $41{ }^{\circ} \mathrm{C}$, o registro de incidência de lesões esofágicas varia de $6 \%$ a $47 \%$ 40,58. Um outro critério que pode ser utilizado, além da TIE absoluta, é o aumento $\geq 1{ }^{\circ} \mathrm{C}$ em relação a TIE basal como limite máximo, durante a aplicação de $\operatorname{RF}^{33}$.

Além disso, para cada $1{ }^{\circ} \mathrm{C}$ de elevação em relação a TIE, há um odds ratio de 1,36 para risco de lesão térmica ${ }^{59}$. Por outro lado, vale ressaltar que existe relato de lesão esofágica com menores graus de aquecimento ${ }^{58}$ ( figura 11) mesmo porque, aquecimentos maiores podem não estar sendo detectados em outras áreas. Assim, apesar do melhor controle das variações da TIE, ainda são descritas lesões térmicas esofágicas ${ }^{60}$. 
Figura 11 - Lesão térmica esofágica.

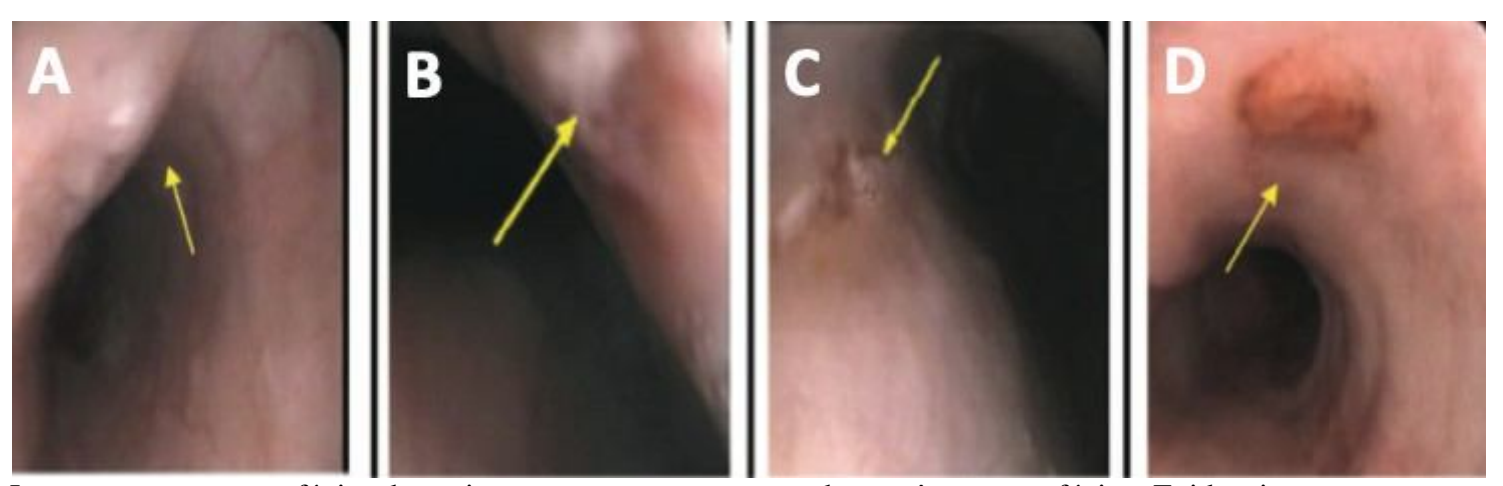

Lesões na mucosa esofágica de pacientes que estavam em uso de termômetro esofágico. Evidenciou-se que quanto maior a temperatura atingida pelo cateter de $\mathrm{RF}$, maior o risco e grau da lesão. Temperatura máxima atingida $\left({ }^{\circ} \mathrm{C}\right)$ : A) 36.5, B) 39.2, C) 39.6 e D) $40.6^{58}$.

Figura 12 - Termômetro intra-esofágico.

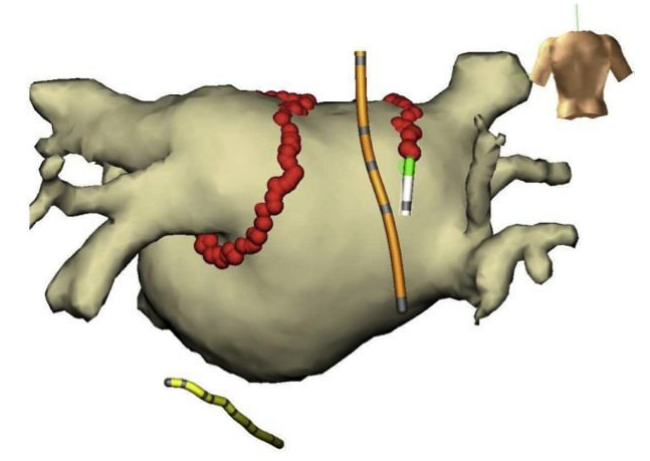

Procedimento de ablação de FA utilizando o sistema Ensite NavX ${ }^{\mathrm{TM}}$ com fusão da imagem da RNM do AE. Visão posterior do AE. O termômetro esofágico está representado na cor laranja. O cateter de RF está representado com a ponta verde. Os pontos onde foi aplicada a RF estão representados em vermelho ${ }^{60}$.

Sternick et al., relataram um caso de ablação de fibrilação atrial no qual houve lesão esofágica. A morfologia das lesões era semelhante aos polos de temperatura do termômetro esofágico e, por isso, acreditaram que o ocorrido poderia ser justificado por um possível efeito antena (efeito por indução) entre ponta do cateter de RF e termômetro ${ }^{61}$.

Seguindo a mesma linha, Müller et al., avaliaram um grupo de 80 pacientes, por EDA, dois dias após ter sido realizada a ablação da FA. Os autores levantaram evidências de que o grupo no qual foi utilizado o termômetro esofágico apresentou um número maior de lesões no esôfago quando comparado ao grupo de que não fez uso do mesmo (30\% vs. 2,5\%, p<0,01). E na regressão logística multivariada, o único preditor de risco independente para formação de 
lesões esofágicas foi a presença do termômetro (odds ratio 16,7, p<0,01) ${ }^{62}$. Em ambos os trabalhos $^{61,62}$, o termômetro que fora utilizado não apresentava isolamento elétrico dos polos de temperatura e, assim, poderia ter o potencial de apresentar o efeito antena com a ponta do cateter de RF, justificando a lesão esofágica mediada pelo termômetro (Figura 13).

Figura 13 - Termômetro SensiTherm.

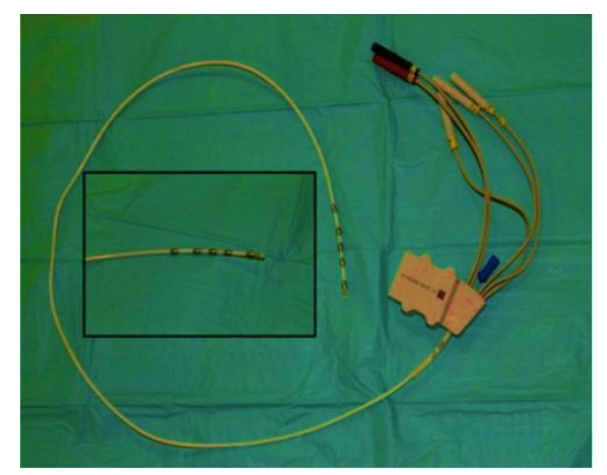

Esse dispositivo tem 7F, não é deflectível, possui 3 eletrodos centrais para monitorar a temperatura e 1 distal e proximal com funções de estimulação e sensibilidade. Este modelo não possui isolamento elétrico nos pólos metálicos ${ }^{62}$.

Em posterior publicação, Halbfass et al., avaliaram qual seria o risco da utilização de um termômetro esofágico, agora, com isolamento elétrico nos seus pólos de temperatura. A incidência de lesões esofágicas foi semelhante no grupo com a utilização e no grupo sem a utilização do dispositivo, respectivamente (7,5\% vs. 10\%,p=1,0). Assim, os autores concluíram que a utilização de termômetros com isolamento elétrico não parece aumentar o risco de lesões esofágicas $^{63}$.

\subsubsection{Refrigeração contínua do esôfago}

Tenta-se prevenir o aquecimento do esôfago através do seu resfriamento por meio de sistemas com balão intra-esofágico $^{64}$, (Figura 14) ou, até mesmo, por meio da instilação de água gelada intra-luminal. No entanto, mesmo havendo uma adequada refrigeração da mucosa, não é garantido o suficiente resfriamento de toda a espessura da parede do esôfago ${ }^{65}$. Há, também, o risco de aproximar a parede anterior do esôfago da parede posterior do AE quando o balão é insuflado e, consequentemente, aumentar o risco de lesão esofágica. 
Figura 14 - Sistema de refrigeração intra-esofágico.

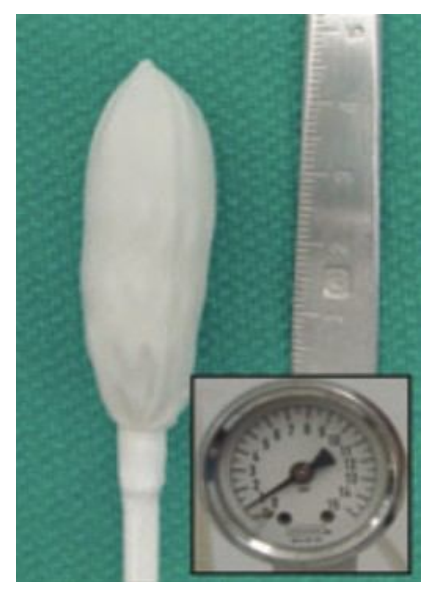

Dispositivo de apoio durante ablação de $\mathrm{FA}$ por $\mathrm{RF}^{64}$.

As técnicas descritas previamente visam a proteção do esôfago contra os efeitos térmicos indesejados da RF. Isto é possível por meio da localização da posição do esôfago em relação ao AE, redução da potência e duração da RF, monitoramento da TIE ou por sistemas de resfriamento do lúmen esofágico. No entanto, apesar de todas as técnicas buscarem reduzir o problema do aquecimento esofágico, nenhuma é capaz de modificar a sua posição e desviá-lo para áreas de menor risco quando o aquecimento se torna presente. Além do que, nesta situação, pode haver limitação ou mesmo impossibilidade da aplicação da potência e tempo necessários de RF.

Considerando que o esôfago é uma víscera móvel, na maioria dos pacientes, torna-se conveniente uma técnica que tenha, além da capacidade detecção do aquecimento, a capacidade de modificar a posição do esôfago afastando-o das áreas de risco. Deste modo, o desvio mecânico do esôfago oferece tais características quando associado a utilização do termômetro esofágico.

\subsubsection{Desvio mecânico do esôfago}

A partir da consideração anatômica de que o esôfago tem sua posição muito próxima da parede posterior do AE, trajeto variável, possui motilidade e também anatomia complexa, foi aventada a possibilidade de deslocar este órgão das regiões de risco de aquecimento através de dispositivos inseridos na luz esofágica. 
Esta técnica foi idealizada por Pachón et al. em 2005 e executada através do desvio mecânico contralateral do esôfago por meio da utilização do transdutor do ETE (tETE) e uso de termômetro esofágico monopolar ${ }^{66}$ (Figura 15). De acordo com a região a ser aplicada a RF, o esôfago é deslocado contra lateralmente, através de manipulação do tETE, obtendo-se, na grande maioria dos casos, um distanciamento suficiente para evitar o seu aquecimento e suas potenciais complicações relacionadas.

Esta técnica é utilizada rotineiramente no serviço de arritmias SEMAP/HCor, em São Paulo. Além de ser utilizada para realizar o desvio mecânico, o tETE é fundamental para realizar o ETE durante a ablação, para a pesquisa de trombos intracavitários, para auxiliar na punção transeptal, para monitorar microbolhas e para a avaliação do espaço pericárdico. No estudo que descreveu a técnica ${ }^{66}$, não foi observado nenhum caso de fístula atrioesofágica ou complicação maior relacionada ao esôfago nos 704 pacientes estudados.

Figura 15 - Desvio mecânico do esôfago.

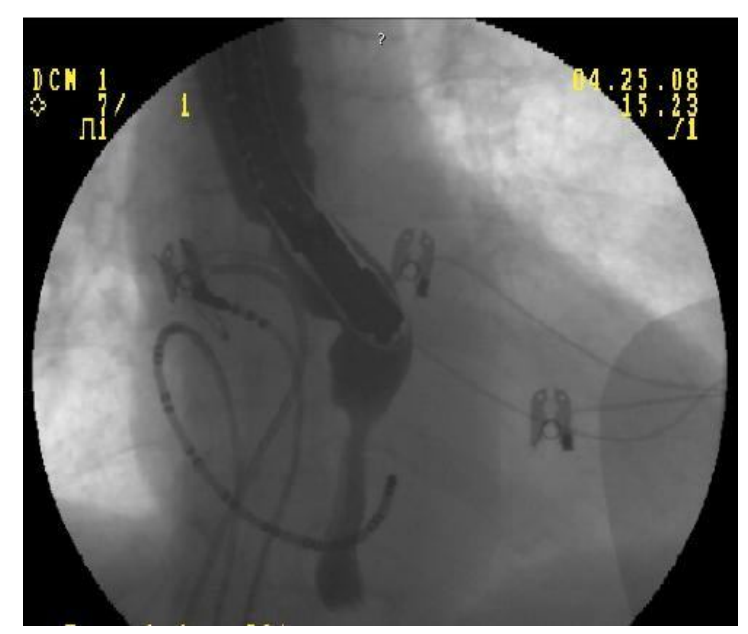

Demonstração do DM através de meio de contraste com bário (Imagem gentilmente cedida pelo Dr. Pachón).

Em 2009, Chugh et al. também utilizaram esta técnica, no entanto, realizaram o desvio mecânico do esôfago com o tETE e, o qual foi retirado em seguida, com a justificativa de possível efeito antena (efeito por indução entre termômetro e cateter de RF). Nessa condição, houve o retorno do esôfago à sua posição basal em 7 de 9 casos, sendo assim, pouco eficaz ${ }^{67}$.

Mais recentemente, em 2012, Koruth et al. realizaram o desvio mecânico em 20 pacientes por meio do uso de um guia pré-moldado que foi inserido numa sonda nasogástrica. Assim, o esôfago poderia ser deslocado para regiões mais seguras, evitando ou atenuando o seu aquecimento. Os autores descreveram que a TIE atingiu valores $\geq 38,5^{\circ} \mathrm{C} \mathrm{em} 3 / 20$ casos e em 
nenhum paciente houve registro acima de $40^{\circ} \mathrm{C}$. Dos 20 pacientes incluídos, $63 \%$ apresentaram lesões esofágicas superficiais relacionadas à trauma, mas sem repercussão clínica ${ }^{68}$. Na SEMAP-HCor esta guia foi testada, porém verificou-se que não possui torque suficiente para deslocar o esôfago em todos os casos sendo menos eficiente em relação ao tETE, apesar de ter a vantagem de projetar menos o esôfago em direção ao $\mathrm{AE}$.

Outra alternativa de surgimento recente, é o $\mathrm{DV} 8^{69}$ que promove o desvio do esôfago por um sistema pneumático. Permite um bom desvio, porém, apresenta manuseio mais trabalhoso, pelo seu sistema mais complexo, quando comparado ao tETE quando temos que realizar desvios repetidos. 


\section{HIPÓTESE}

O desvio lateral do esôfago para um ponto distante da aplicação da RF evita o seu aquecimento e diminui o risco de lesão esofágica, detectáveis ou não por EDA. O monitoramento longitudinal do esôfago com termômetro multicanal, seria um método seguro para comprovar ou não a eficácia do afastamento mecânico na prevenção do aquecimento esofágico. 


\section{JUSTIFICATIVA}

A hipótese baseia-se no fato de que o esôfago é um órgão móvel, na maioria dos pacientes. Portanto, o grau de afastamento obtido pelo deslocamento mecânico com a manipulação do tETE seria suficiente para impedir seu aquecimento, permitindo ablações completas, mesmo utilizando técnicas mais extensas. Além disso, este mesmo transdutor pode ser posicionado de forma fixa, impedindo o retorno do esôfago para uma área de risco de aquecimento.

Diversos trabalhos buscam monitorar a temperatura do esôfago com termômetros ${ }^{26,70}$. Entretanto, devido à complexidade anatômica deste órgão, pode ocorrer aquecimento fora do alcance do termômetro.

Neste estudo, utilizou-se um termômetro multicanal computadorizado que permite a monitoração simultânea de 12 pontos ao longo do esôfago. Esse diferencial em relação ao trabalho inicial ${ }^{66}$ possibilita maior sensibilidade e segurança quanto a possíveis efeitos térmicos indesejados. 
5. OBJETIVOS 


\section{OBJETIVOS}

OBJETIVO PRIMÁRIO:

- avaliar a eficácia e segurança da técnica do desvio mecânico do esôfago na prevenção de aquecimento mínimo esofágico $\left(\geq 0,5^{\circ} \mathrm{C}\right)$ através da medida da TIE durante a ablação da FA utilizando um sistema de termômetro multicanal.

\section{OBJETIVOS SECUNDÁRIOS:}

- obter a mensuração da amplitude do desvio do esôfago;

- avaliar a estabilidade da posição do esôfago após a realização do desvio mecânico. 
6. CASUÍSTICAEMÉTODOS 


\section{CASUÍSTICA E MÉTOdOS}

Entre fevereiro de 2016 até dezembro de 2018, 55 pacientes foram incluídos a partir dos casos regulares atendidos no SEMAP e HCor. Todos eles apresentavam diagnóstico de FA paroxística ou persistente, com indicação de ablação por cateter de radiofrequência, de acordo com as diretrizes brasileiras de fibrilação atrial ${ }^{71}$.

As seções seguintes apresentarão um detalhamento maior sobre o estudo eletrofisiológico invasivo e sobre o protocolo para a aplicação de RF, incluindo a descrição da metodologia utilizada para medir o desvio mecânico e, com base nessa medida, avaliar o seu sucesso (Fluxograma 1), e avaliar a sua capacidade de prevenir o aumento de temperatura.

Fluxograma 1 - A dinâmica do protocolo da tese

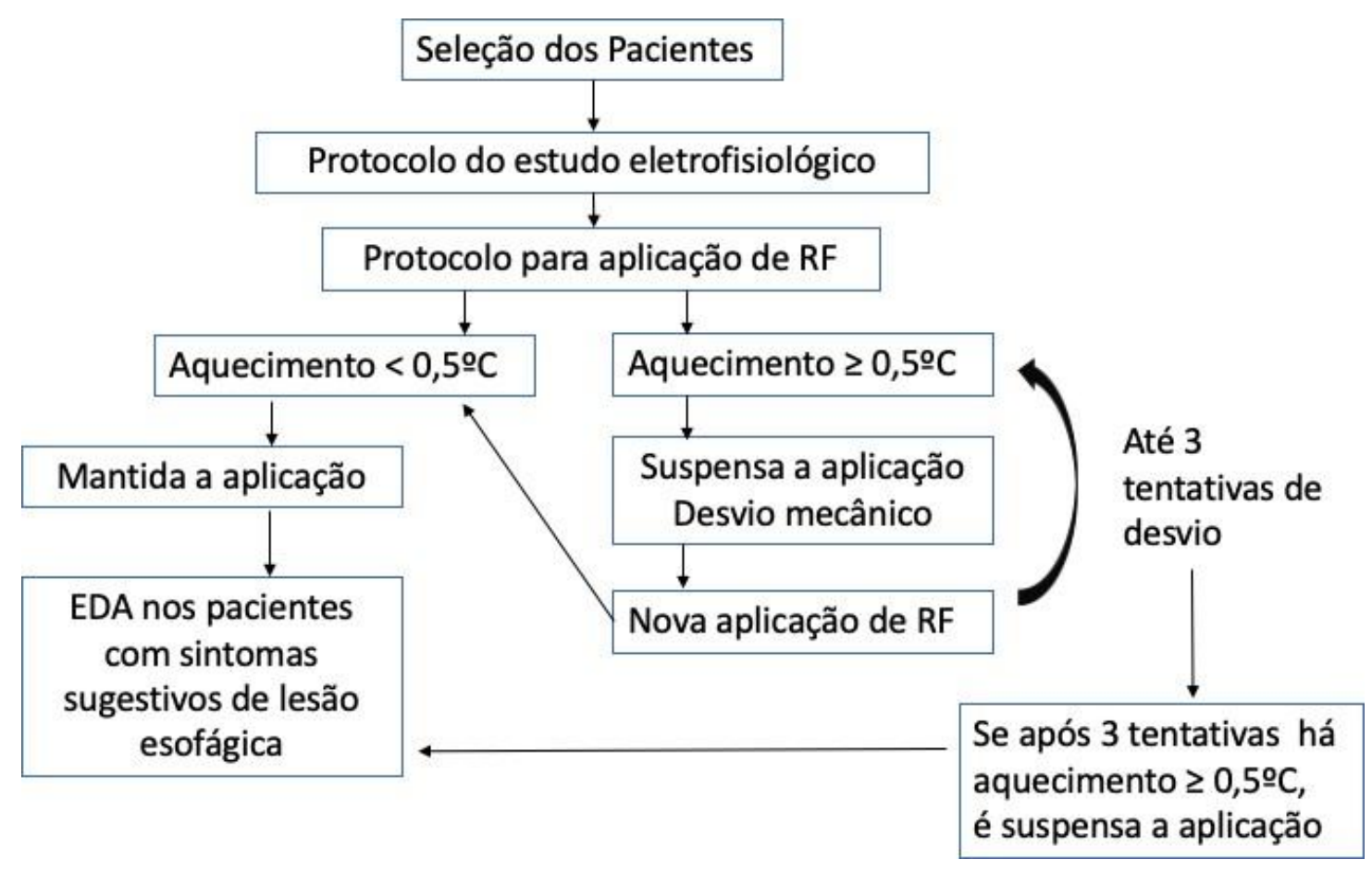




\subsection{Protocolo do estudo eletrofisiológico}

Os anticoagulantes (Dabigatrana, Rivaroxabana ou Apixabana) foram suspensos por, no mínimo, $48 \mathrm{~h}$ antes do procedimento e antiarrítmicos por, pelo menos, 5 meias-vidas. Após terem assinado o termo de consentimento livre e esclarecido os pacientes foram submetidos à anestesia geral endovenosa. O tETE (Philips, modelo X7-2t) era inserido para pesquisa de trombo intracavitário, presença de forame oval patente, avaliação do espaço pericárdico e janela para punção transeptal.

Após o acesso ao AE através da punção transeptal única, guiada pelo ETE, era administrada heparina não-fracionada com o objetivo de manter o valor do tempo de coagulação ativado entre 300 a 400 segundos. Em todos os casos foi utilizado o sistema eletroanatômico 3D, Ensite Velocity® System (Saint Jude Medical) para auxiliar no posicionamento dos cateteres, mapeamento e ablação. Um cateter circular diagnóstico era utilizado para criar o modelo eletroanatômico 3D do AE e AD.

Antes de serem iniciadas as aplicações de RF, o termômetro esofágico de 12 polos (Circa Scientific - Model CS-1000 - Figura 16) era inserido com o intuito do monitorar as possíveis variações da TIE. O polo distal do termômetro era posicionado ao nível do esfíncter esofagiano inferior. Sempre que necessário, o dispositivo era ajustado para cobrir rigorosamente as localizações mais próximas do cateter de RF.

Figura 16 - Termômetro esofágico e monitor.
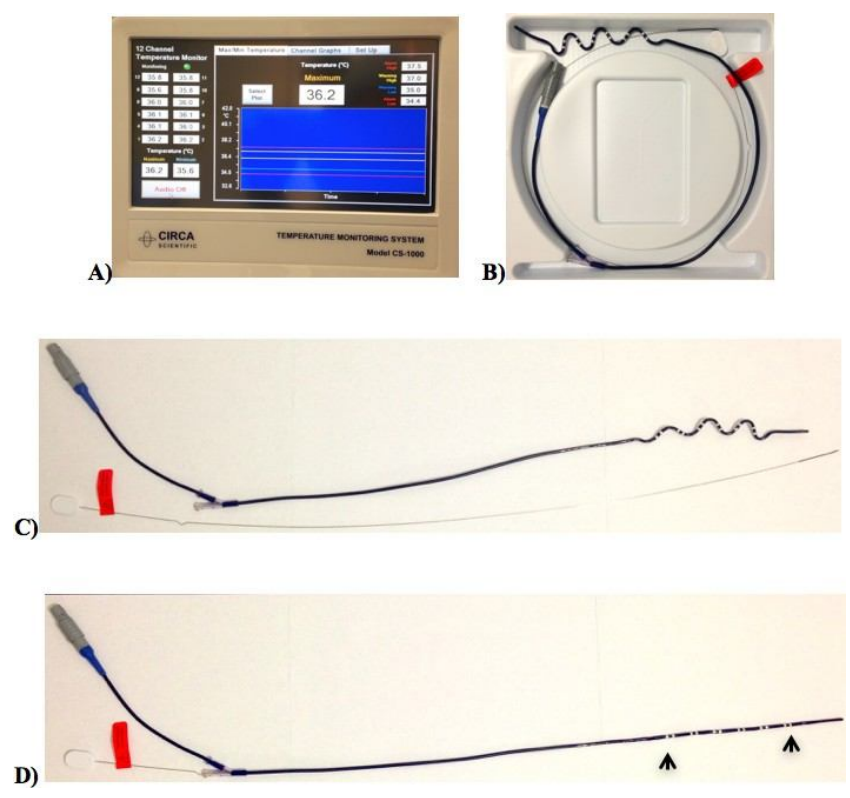
A) Monitor do termômetro esofágico. B) Termômetro esofágico na embalagem. C) Termômetro esofágico com o fio guia fora de seu lúmen. D) Termômetro esofágico com o fio guia introduzido. As setas indicam quatro dos doze pólos de temperatura que são distribuídos aos pares.

Os cateteres irrigados de RF utilizados foram: EZ Steer ThermoCool ${ }^{\circledR}$ (Biosense Webster Inc.), fluxo de $17 \mathrm{ml} / \mathrm{min}$ e FlexAbility® (Saint Jude Medical), fluxo de $13 \mathrm{ml} / \mathrm{min}$, ambos com temperatura máxima de $43^{\circ} \mathrm{C}$ e potência de $30 \mathrm{~W}$, durante todo o procedimento.

As ablações eram iniciadas pela abordagem antral das VP até que fosse comprovado o seu isolamento elétrico (bloqueio de entrada, de saída ou ritmo intrínseco de VP) e abordagem

guiada por potenciais do tipo "ninhos de FA" era abordado por meio do isolamento da veia cava superior e da região compreendida entre a borda medial da veia cava superior até a fossa oval e, desta, até a veia cava inferior, em busca dos mesmos potenciais tipo "ninhos de FA". Posteriormente, foram realizados testes através da estimulação atrial progressiva até 300 ppm, tanto no átrio esquerdo como no átrio direito para avaliar a estabilidade elétrica atrial e, eventualmente, induzir taquicardias residuais como a $\mathrm{TBK}^{16,17}$.

\subsubsection{Protocolo do desvio mecânico}

Inicialmente, as aplicações de RF eram realizadas sem a presença do tETE, tendo a TIE rigorosamente controlada pelo termômetro multicanal posicionado adequadamente no esôfago. A aplicação de RF era mantida desde que o aumento da TIE fosse $<0,5^{\circ} \mathrm{C}$.

Entretanto, quando ocorria aquecimento $\left(\geq 0,5^{\circ} \mathrm{C}\right)$, a $\mathrm{RF}$ era imediatamente interrompida e o tETE era posicionado ao nível do cateter de RF, visualizado por meio da fluoroscopia. Então, era realizado o desvio mecânico, através do acionamento do mecanismo do tETE, para o lado contralateral, de forma a afastar o esôfago das regiões de risco de aquecimento (Figura 17 e Figura 18).

Assim, era retomada a aplicação de RF no mesmo local, mantendo-se a monitoração da TIE. Caso houvesse novo aumento de temperatura $\geq 0,5{ }^{\circ} \mathrm{C}$, mesmo com o DM, a RF era novamente suspensa e realizado novo DM. Limitou-se em 3 o número de tentativas de DM, 
sendo considerado insucesso se após a terceira tentativa houvesse persistência do aquecimento. Nesta situação, a liberação de RF era definitivamente interrompida naquela região.

Figura 17 - DM com contraste esofágico 1.

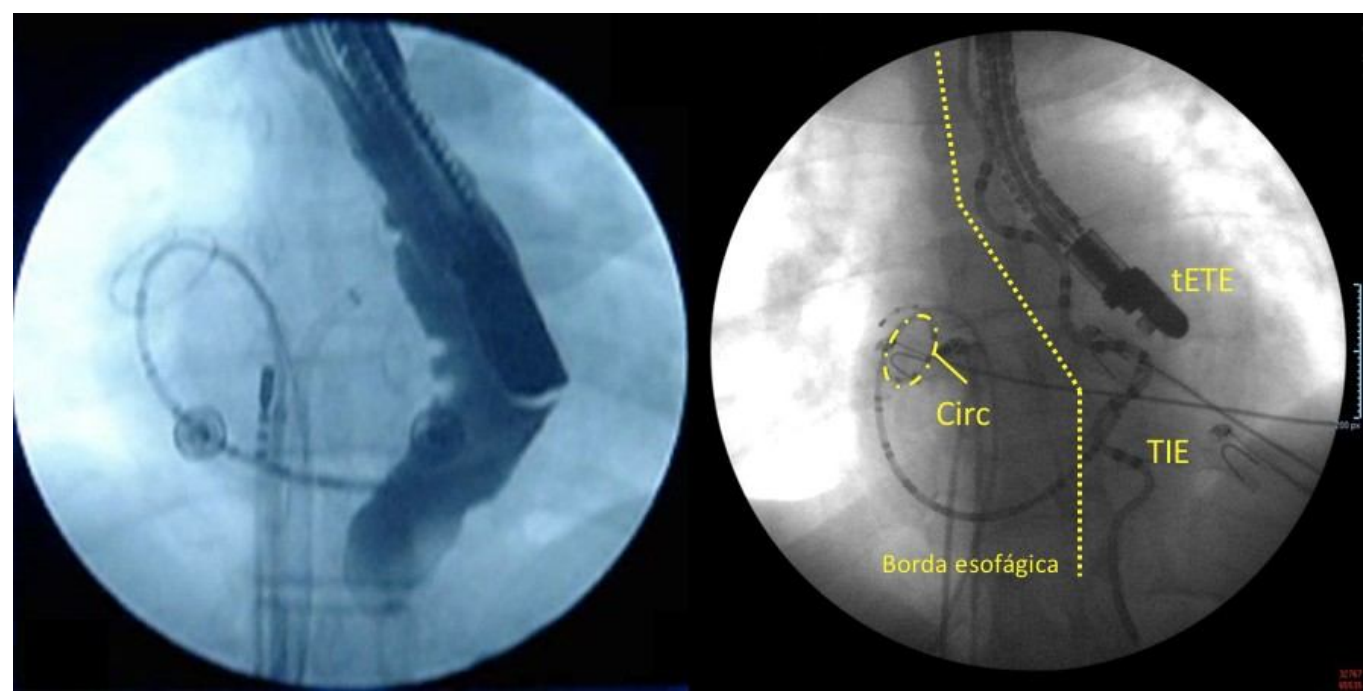

A) Desvio mecânico do esôfago contrastado com bário B) Desvio mecânico na presença do termômetro delimitando a borda ipsilateral do esôfago. É possível notar que a borda de risco de aquecimento acompanha o desvio do esôfago, na maioria dos casos. TIE: termômetro intraesofágico. tETE: transdutor do ecocardiograma transesofágico. CIRC: cateter circular de mapeamento (decapolar).

Figura 18 - DM com contraste esofágico 2.

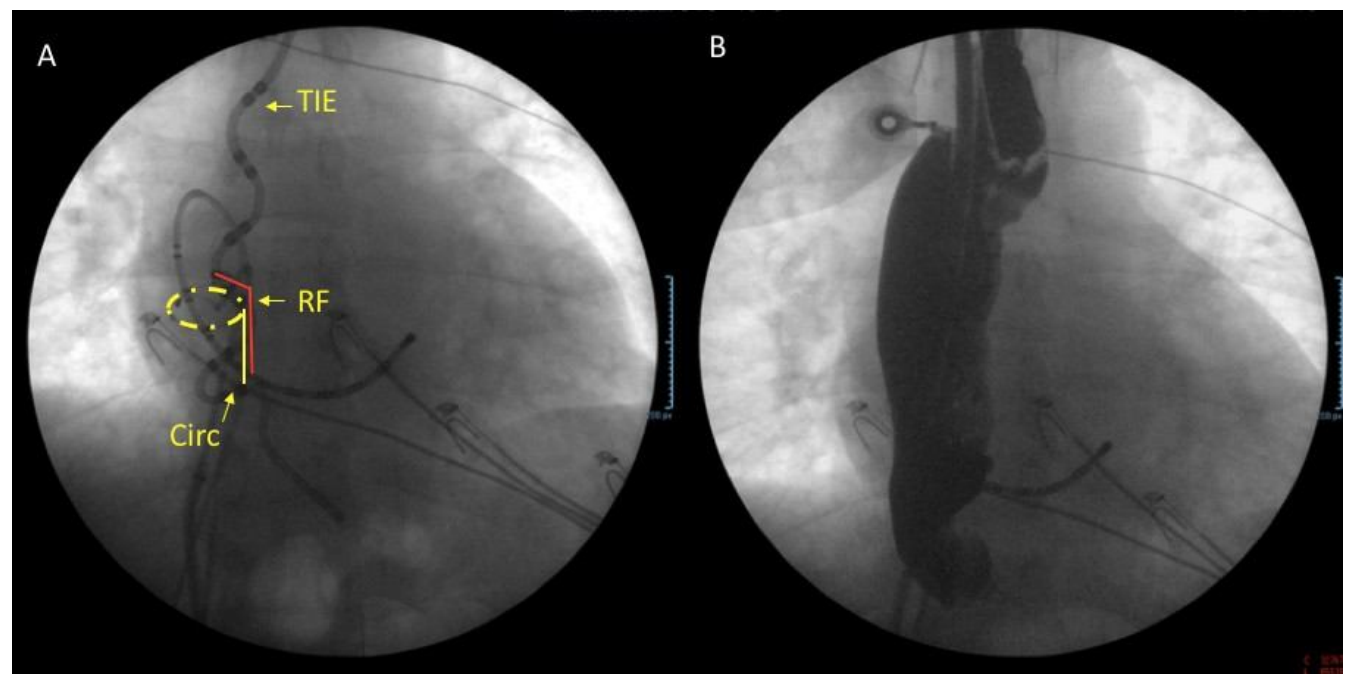




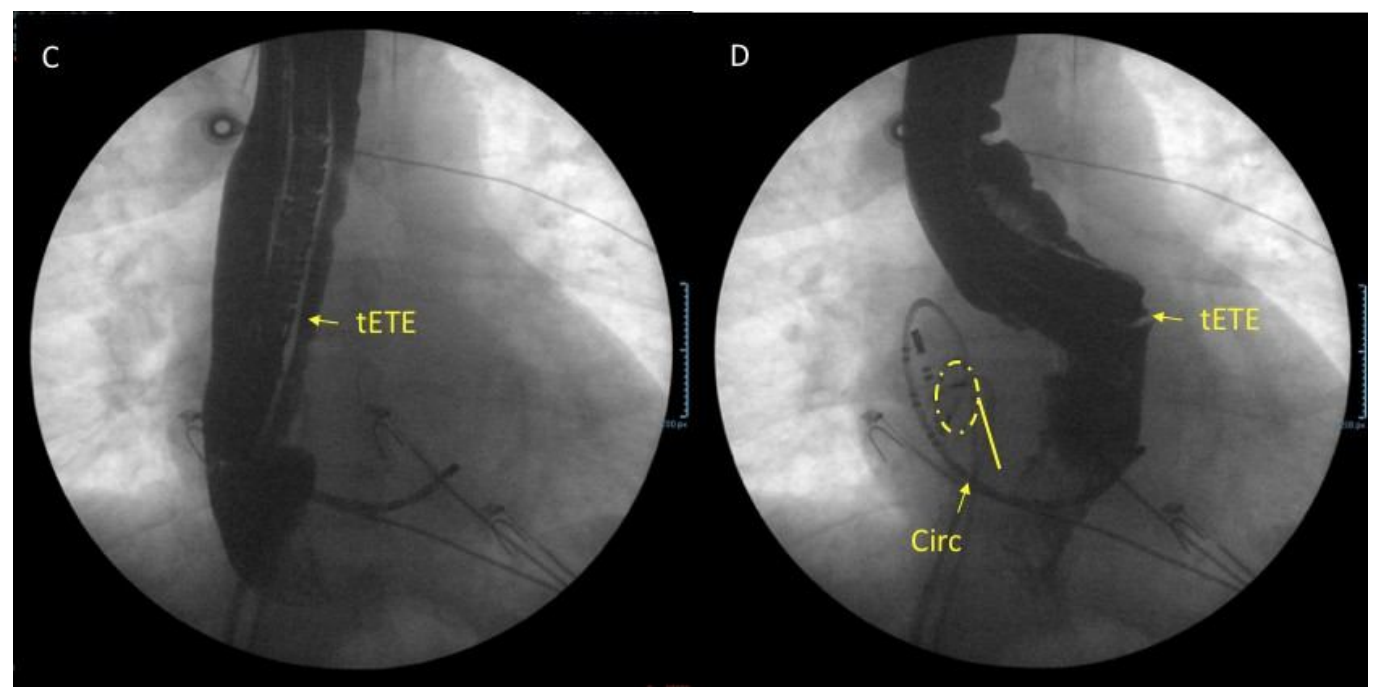

A. Termômetro esofágico normoposicionado, cateter circular de mapeamento localizado no antro da veia pulmonar inferior direita juntamente com o cateter de RF. Pelo trajeto do esôfago demonstrado pelo termômetro, podemos perceber que há sobreposição entre VP e esôfago. B. Realizada infusão de meio de contraste baritado. C. o tETE foi introduzido até o nível do cateter de RF. D. O desvio mecânico contralateral do esôfago afasta a borda de risco e, então, é possível visualizar novamente o cateter circular e de RF que estavam sobrepostos ao esôfago contrastado. RF: cateter de radiofrequência. tETE: transdutor do ecocardiograma transtorácico. Circ: cateter circular de mapeamento.

A seguir, na Figura 19, o esôfago foi dividido por meio de duas linhas verticais formando três regiões: direita (D), central (C) e esquerda (E). Assim, foi possível definir a posição deste órgão em relação ao AE.

Figura 19 - Lateralidade do esôfago.

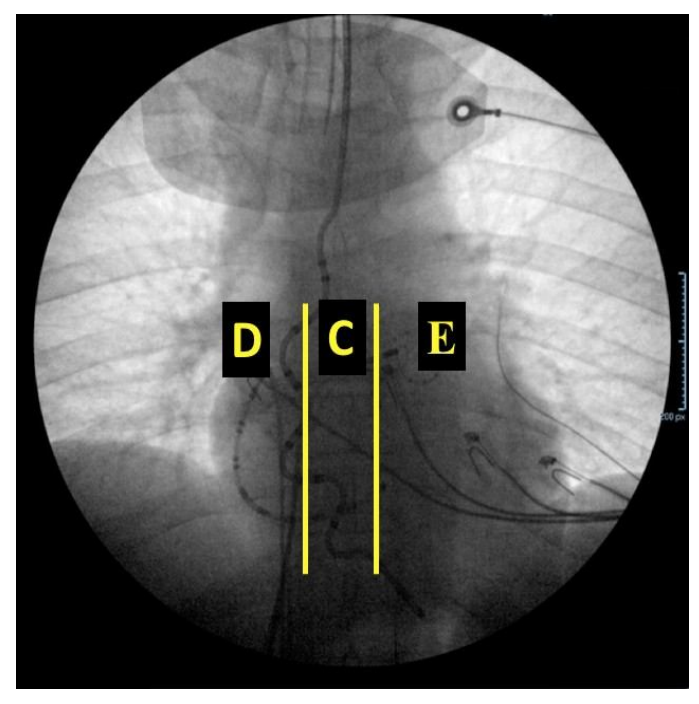


Para definir a posição do esôfago em relação ao $\mathrm{AE}$, esse foi dividido por meio linhas em três regiões: $\mathrm{D}=$ direita, $\mathrm{C}=$ central e $\mathrm{E}=$ esquerda.

A medida da amplitude do DM foi realizada através de software de visualização de imagem (Pré-visualização, Versão 9.0 (909.12), Apple Inc.). Cada medida foi corrigida devido à possíveis distorções decorrentes das variações de pixels entre os aparelhos de radioscopia e a distância do intensificador de imagem em relação ao tórax do paciente. Como valor referência, utilizou-se o corpo do tETE, que possui 10mm de diâmetro. A partir disso, duas medidas eram realizadas: a distância basal e desvio mecânico.

Distância basal (DB): esta medida corresponde à distância entre a borda medial do cateter circular "ponto zero" até a borda ipsilateral do esôfago (borda de risco de aquecimento). Sendo que, esta última era definida pelo contorno do termômetro esofágico ou do tETE (a que estiver mais próxima do cateter circular). O cateter circular, localizado no antro da veia pulmonar era utilizado como marcador desta estrutura (figura 20).

Figura 20 - Distância basal.

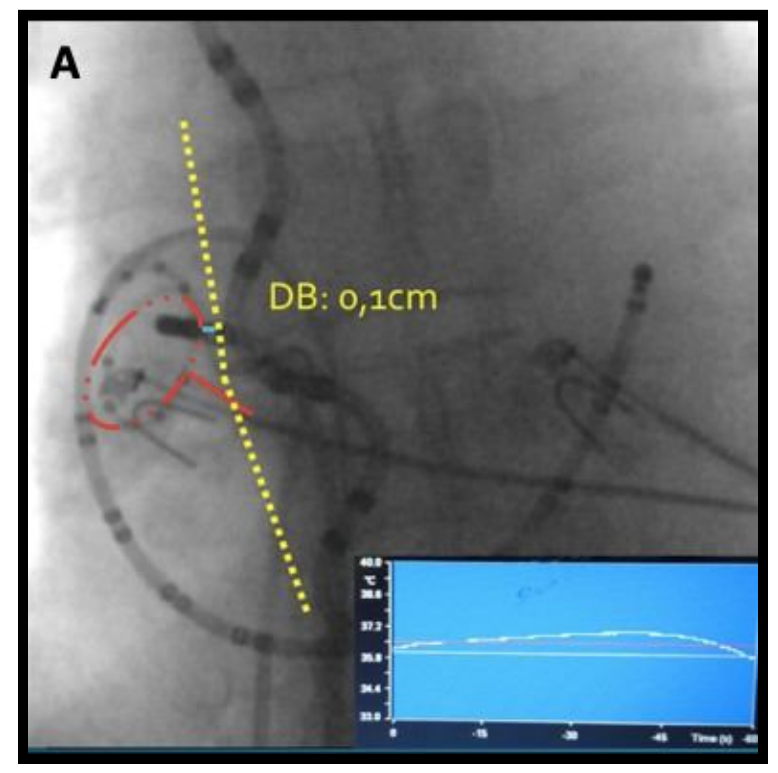

Posição basal do esôfago apenas com o termômetro inserido, demonstrando uma distância muito próxima entre o esôfago e antro da VPID (DB: 0,1 cm). A linha azul corresponde à DB, distância entre a borda medial do cateter circular localizado no antro da VP ("ponto zero") até a borda ipsilateral do esôfago, demonstrada pela linha amarela. 
Desvio mecânico (DM): após identificado o aumento da TIE, o tETE era introduzido ao nível do cateter de RF e realizado o DM. A amplitude do desvio era considerada como a distância entre a borda medial do cateter circular "ponto zero" até a borda ipsilateral do esôfago (borda de risco de aquecimento) definida pela sombra do termômetro intra-esofágico, tETE ou contraste (Figura 21 e Figura 22).

Ao retirar a guia de manipulação, o termômetro intra-esofágico assume uma conformação sinusoidal que se adapta aos limites laterais do esôfago, sendo um bom marcador de suas bordas, confirmado nos casos em que adicionalmente foi utilizado contraste baritado. Assim, na ausência do contraste, definimos que a borda de risco estaria na região justaposta à sombra radiológica do termômetro.

A presença nas figuras do sinal de subtração (-) em frente a algum número referente às medidas de distância basal indica que há sobreposição do esôfago em relação a borda medial do cateter circular.

Assim, o valor do DM sempre será estabelecido pela diferença entre posição inicial (DB) e posição final (DM).

Figura 21 - Desvio mecânico 1

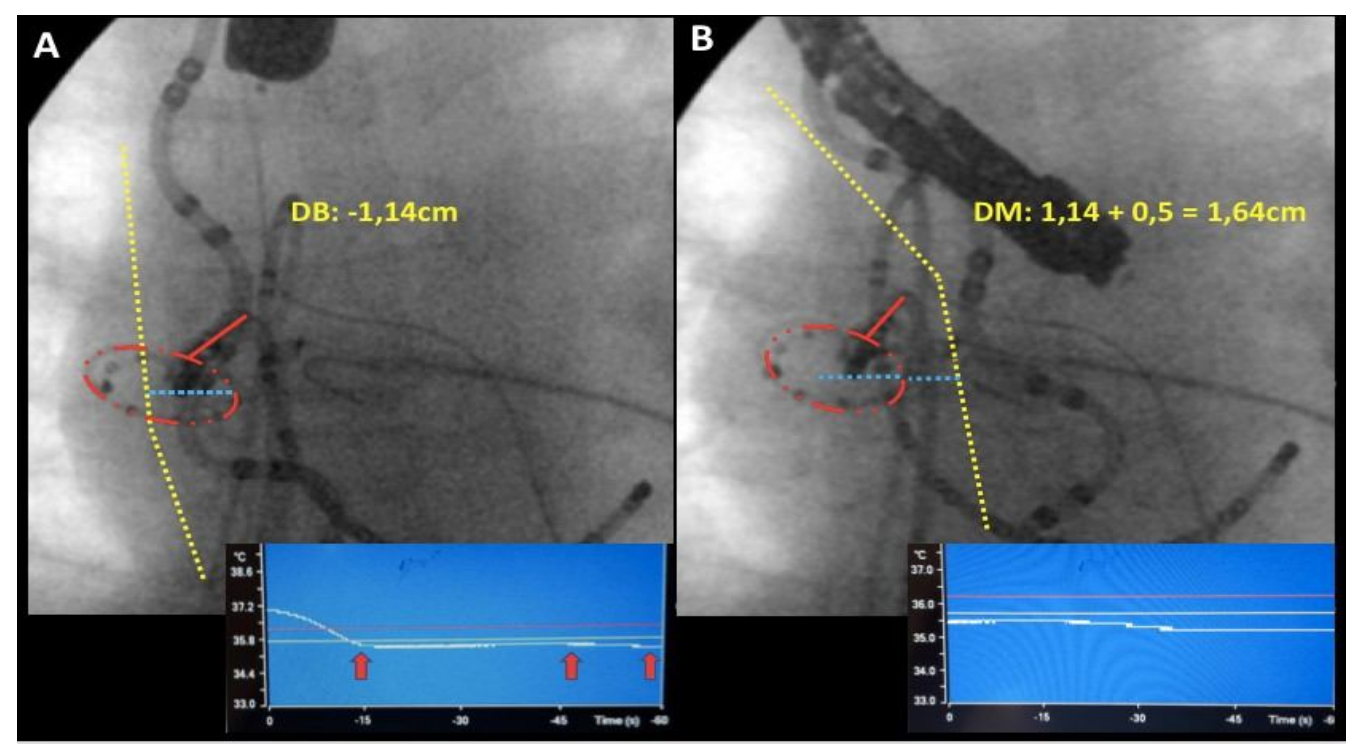

A) Sobreposição entre a veia pulmonar inferior direta e esôfago, DB: -1,14 cm. Quando foi realizada a aplicação de $\mathrm{RF}$ na região posterior da VP, houve um rápido aquecimento até $37,2^{\circ} \mathrm{C}$. Antes de atingir essa temperatura, já tinha sido suspensa a aplicação de RF. B) Realizado o DM =1,14 +0,5 =1,64 cm. No gráfico, ainda houve subida lenta da temperatura de até $0,3{ }^{\circ} \mathrm{C}$, o que permitiu o completo isolamento da VP, semcomplicações. 
Figura 22 - Desvio mecânico 2

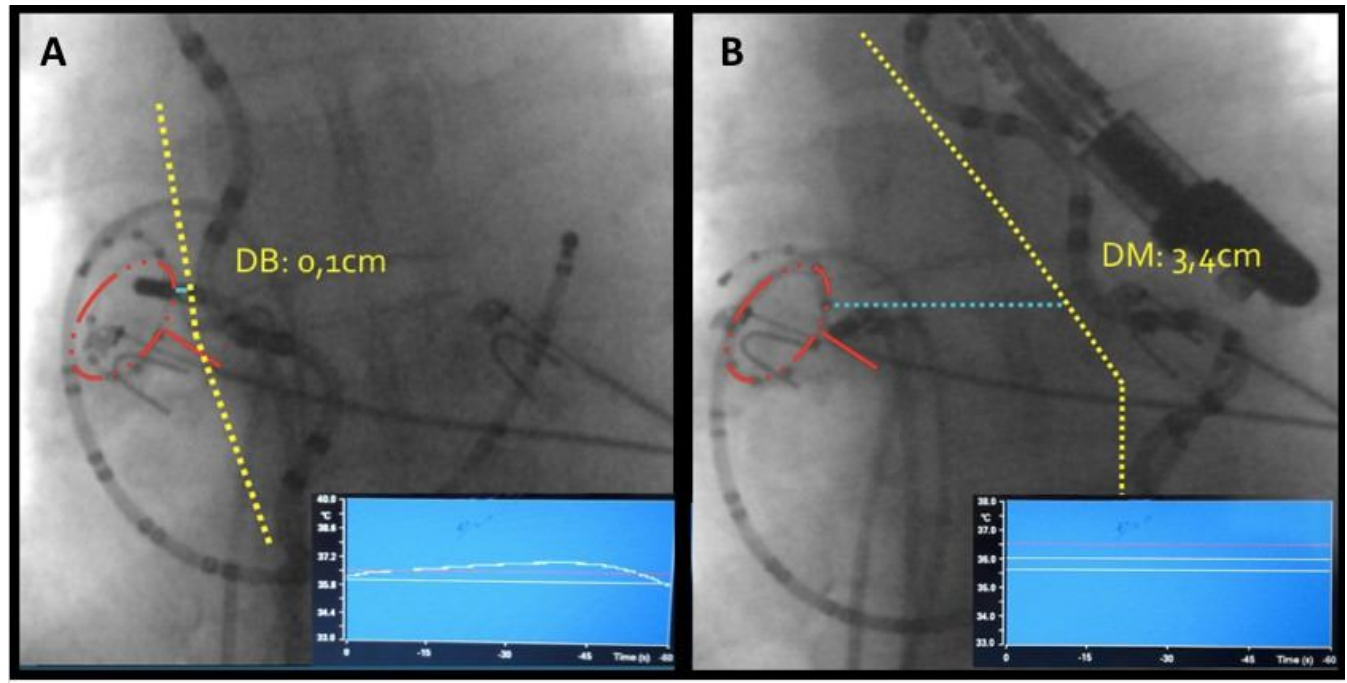

A) O tETE é inserido no esôfago, posicionado ao nível do cateter de RF e realizado o desvio contra-lateral. O objetivo é afastar o esôfago para um ponto distante do risco de aquecimento. B) O DM foi de 3,5cm - 0,1 cm da posição basal $=3,4 \mathrm{~cm}$. A linha amarela delimita a borda do esôfago ipsilateral (de risco). Nesta situação, nota-se que gráfico do monitor do termômetro não apresenta variação de temperatura após a liberação de RF.

Figura 23 - Ausência de elevação de temperatura após o DM.

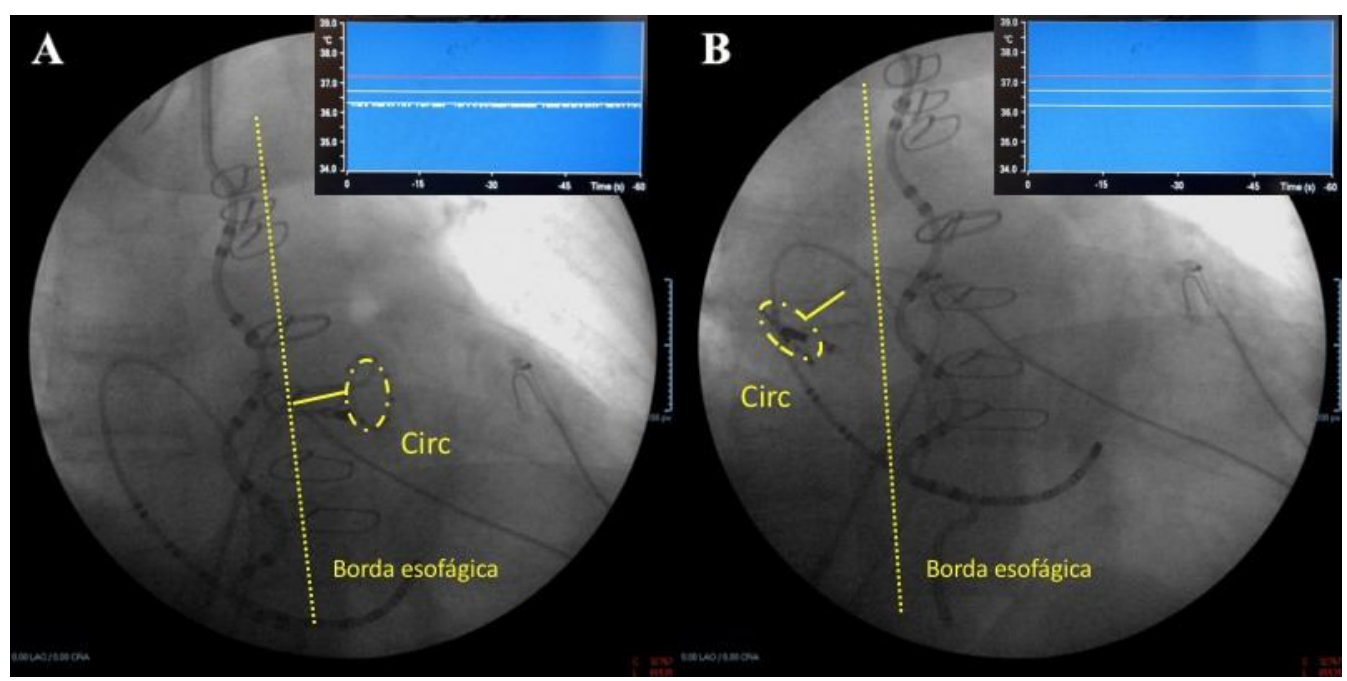

A) e B) Aplicação de RF nas veias pulmonares a esquerda e a direita, sem que houvesse aumento da TIE, conforme registro do monitor do termômetro esofágico. 


\subsubsection{Protocolo do critério temperatura}

Para definir o critério de sucesso, foram utilizadas duas referências de TIE durante a aplicação de RF: variação $<0,5{ }^{\circ} \mathrm{C}$ em relação a temperatura basal e valor absoluto de temperatura $<38,5^{\circ} \mathrm{C}$.

Variação $<0,5{ }^{\circ} \mathrm{C}$ em relação a temperatura basal: foi considerado sucesso quando era possível aplicar toda a RF necessária ao procedimento com variações da TIE $<0,5^{\circ} \mathrm{C}$. Foram considerados insucessos os casos que apresentavam elevação da temperatura $\geq 0,5{ }^{\circ} \mathrm{C}$ após três tentativas de desvio mecânico.

Valor absoluto de temperatura $<38,5^{\circ} \mathrm{C}$ : foram considerados sucesso quando a TIE apresentava valores $<38,5^{\circ} \mathrm{C}$ após o desvio mecânico. Foram considerados insucesso qualquer valor $\geq 38,5^{\circ} \mathrm{C}$ após três tentativas de DM.

\subsection{Complicações}

\subsubsection{Complicações mecânicas}

Toda ecocardiografia transesofágica pode ser acompanhada de complicações mecânicas relacionadas à inserção e manipulação do $\mathrm{tETE}^{72}$. Geralmente são constituídas de pequenos hematomas submucosos, tipicamente sem sangramento ativo e, normalmente, sem sintomas subsequentes. Assim, foi considerado como complicação mecânica a presença de hematoma (de qualquer diâmetro), sangramento e erosões da mucosa de aspecto traumático.

\subsubsection{Complicações térmicas}

Estas constituem o objetivo maior deste estudo. Podem ser divididas em detectáveis por EDA, sendo representadas por eritema, ulceração e perfuração da parede esofágica e em não detectáveis por EDA, como a gastroparesia que é consequente à lesão dos plexos nervosos.

A endoscopia digestiva alta (EDA) foi indicada nos casos em que os sintomas justificaram a sua realização, tais como sangramento digestivo, odinofagia ou disfagia pósablação. As visitas foram rotineiramente realizadas duas vezes por dia durante o período de internação e, adicionalmente, quando houvesse mudança clínica. Após a alta, os pacientes foram reavaliados em 30, 60 e 90 dias. 


\subsection{Critérios de inclusão e exclusão}

Critérios de inclusão:

- idade > 18 anos;

- fibrilação atrial paroxística ou persistente com indicação de ablação conforme as diretrizes brasileiras atuais ${ }^{71}$;

- assinatura do termo de consentimento livre e esclarecido (TCLE).

Critérios de exclusão:

- história clínica de cirurgia esofágica, neoplasia, megaesôfago, esôfago de Barret, varizes esofágicas ou qualquer outra patologia que contra-indicasse a manipulação do esôfago;

- discrasia sanguínea hemorrágica;

- intolerância ou impossibilidade de uso de anticoagulantes;

- presença de trombo intracavitário;

- demais contraindicações para ablação de FA;

- impossibilidade de acesso esofágico com tETE;

- recusa em assinar o TCLE.

\subsection{Abrangência da amostra}

Devido a ausência de trabalhos semelhantes pregressos no momento da concepção da tese, foi definido como 20 o número de pacientes que deveriam ser incluídos na fase inicial. Entretanto, este valor seria modificado conforme a necessidade, após avaliação estatística no decorrer do estudo. Trabalhos semelhantes e posteriores de outros autores utilizaram 9 e 20 casos, respectivamente ${ }^{67,68}$. Devido não ter sido observado número significativo de complicações, o número foi elevado a 55 por razões de oportunidade.

\subsection{Coleta de dados}

Os dados do presente estudo foram coletados no laboratório de eletrofisiologia do serviço de arritmias SEMAP/HCor e sendo anotados em formulários Web individuais para cada 
paciente. $\mathrm{O}$ banco de dados para esta tese foi constituído pelos dados coletados que foram tabulados em planilha Excel®, com as imagens arquivadas em cloud-computing.

\subsection{Metodologia da análise estatística}

As variáveis obtidas foram divididas em categóricas e contínuas e, posteriormente, avaliadas de acordo com testes estatísticos específicos para cada tipo de variável e de distribuição. Para o tratamento estatístico, foi utilizado o software estatístico SPSS. Para avaliação da curva de distribuição da amostra utilizou-se o teste de Shapiro-Wilk e, para a análise estatística, o teste t de Student, bicaudal e pareado.

\subsection{Riscos e benefícios}

O risco de complicações do presente estudo está relacionado ao risco do procedimento de ablação da FA no serviço Semap/HCor, ou seja, sem agregar risco adicional, já que o DMe o ETE são realizados rotineiramente em todas as ablações de FA do serviço.

\subsection{Sigilo, privacidade e confidencialidade dos dados coletados:}

Os dados coletados de cada paciente durante o estudo são sigilosos e confidenciais, e permanecerão arquivados pelo autor do projeto por um período de cinco anos, e então serão incinerados, conforme resolução C.N.S. N. 196/96. Nesse período, os dados poderão ser solicitados pelos integrantes do Comitê de Ética em Pesquisa do IDPC/HCor para quaisquer consultas que porventura vierem a ser pertinentes. 
7. RESULTADOS 


\section{RESULTADOS}

Apesar de não terem sido analisados como fatores de risco, a idade média dos pacientes foi $54 \pm 14$ (anos), sendo 16 (29\%) do sexo feminino. Quanto ao índice de massa corpórea (IMC $-\mathrm{kg} / \mathrm{m}^{2}$ ) a média foi de $25 \pm 2$, enquanto, o diâmetro atrial $(\mathrm{cm})$ foi de $3,9 \pm 0,6$. Já a fração de ejeção do ventrículo esquerdo (FEVE\%) foi, em média, $65 \pm 6$ e o tempo de radioscopia (min) de $14 \pm 5$. Foram realizados $44(80 \%)$ procedimentos relativos a FA paroxística e $11(20 \%)$ por FA persistente (Tabela 1).

Tabela 1 - Características clínicas gerais dos pacientes n (\%)

\begin{tabular}{ll}
\hline Total de pacientes & $55(100 \%)$ \\
Idade (média $\pm \mathrm{DP})$ & $54 \pm 14$ \\
Sexo feminino & $16(29 \%)$ \\
IMC $\left(\mathrm{kg} / \mathrm{m}^{2}-\right.$ média $\left.\pm \mathrm{DP}\right)$ & $25 \pm 3$ \\
FEVE $(\%$ - média $\pm \mathrm{DP})$ & $65 \pm 6$ \\
Diâmetro atrial $(\mathrm{mm}-$ média $\pm \mathrm{DP})$ & $39 \pm 5$ \\
FA paroxística & $44(80 \%)$ \\
FA persistente & $11(20 \%)$ \\
\hline
\end{tabular}

Todos os procedimentos foram realizados sob anestesia geral endovenosa. A passagem do tETE, como também a do termômetro esofágico, foi realizada em $100 \%$ dos casos. Não foram incluídos casos de reablação. Em relação ao AE, 25 (45\%) pacientes apresentavam o esôfago à direita, 14 (25\%) deslocado à esquerda e 16 (30\%) em posição central (Figura 19).

O desvio mecânico do esôfago foi necessário em 47 (85\%) dos pacientes, pois em 8 (15\%), não foi observado aumento de temperatura $\geq 0,5^{\circ} \mathrm{C}$. Dos pacientes submetidos ao desvio, $6(13 \%)$ apresentaram aumento de temperatura $\geq 0,5^{\circ} \mathrm{C}$ após 3 tentativas de desvio, sendo então interrompida a aplicação de RF naquelas regiões. No entanto, quando o desvio mecânico é analisado pelo critério de temperatura absoluta $\geq 38,5^{\circ} \mathrm{C}$, todos os casos foram concluídos com sucesso através do DM. A temperatura média do esôfago pré-desvio mecânico foi de $37,03{ }^{\circ} \mathrm{C}$ $\pm 0,06 \mathrm{DP}$, e pós-desvio foi de $35,83^{\circ} \mathrm{C} \pm 0,08 \mathrm{DP}$, a qual é muito próxima da temperatura basal, $35,71^{\circ} \mathrm{C} \pm 0,12 \mathrm{DP}$. A posição basal média do esôfago em relação à borda medial do cateter circular foi de $-0,01 \mathrm{~cm} \pm 0,46$ DP e pós-desvio mecânico de 2,25 cm $\pm 1,19$ DP. Não houve qualquer episódio de deslocamento inadvertido do esôfago após o desvio, constatando 
estabilidade da sua posição em $100 \%$ dos casos desde que o tETE estivesse inserido com o mecanismo de desvio (Tabela 2).

Tabela 2 - Características do procedimento n (\%)

\begin{tabular}{ll}
\hline Anestesia geral & $55(100 \%)$ \\
Tempo de radioscopia (min - média \pm DP) & $14 \pm 5$ \\
Reablação & $0(0 \%)$ \\
Posição basal do esôfago & Direita $25(45 \%)$ \\
& Central $16(30 \%)$ \\
Pacientes submetidos ao desvio & Esquerda $14(25 \%)$ \\
Estabilidade do esôfago após o desvio & $47(85 \%)$ \\
Avaliação da eficácia do desvio mecânico: & $47(100 \%)$ \\
Temperatura basal $\left({ }^{\circ} \mathrm{C}-\right.$ média \pm DP) & \\
TIE média pré-desvio $\left({ }^{\circ} \mathrm{C}\right.$ - média \pm DP) & $35,71 \pm 0,12$ \\
TIE média pós-desvio $\left({ }^{\circ} \mathrm{C}\right.$ - média \pm DP) & $37,03 \pm 0,06$ \\
\hline
\end{tabular}

- Valor absoluto de temperatura $<38,5^{\circ} \mathrm{C}$ :

- Desvio com TIE $<38,5^{\circ} \mathrm{C} \quad 47(100 \%)$

- Desvio com TIE $\geq 38,5^{\circ} \mathrm{C} \quad 0(0 \%)$

- Variação $<0,5^{\circ} \mathrm{C}$ em relação à temperatura basal:

- Desvio com $\mathrm{TIE}<0,5^{\circ} \mathrm{C} \quad 41(87 \%)$

- Desvio com TIE $\geq 0,5^{\circ} \mathrm{C} \quad 6(13 \%)$

Posição basal do esôfago ( $\mathrm{cm}-$ média \pm DP) $\quad-0,01 \pm 0,46$

Desvio mecânico (cm - média \pm DP) $\quad 2,25 \pm 1,19$

- Endoscopia digestiva alta: $14(30 \%)$

- Normal $6(43 \%)$

- Complicações esofágicas mecânicas: $\quad 8(57 \%)$

- Hematoma superficial $(<10 \mathrm{~mm})^{*} \quad 7(50 \%)$

- Erosão por trauma mecânico $1(7 \%)$

- Complicações esofágicas térmicas: $0(0 \%)$

- Detectável $0(0 \%)$

- Não detectável $0(0 \%)$ 
*Lesões comumente encontradas na ecocardiografia transesofágica ${ }^{72}$. TIE: temperatura intraesofágica. cm: centímetros. DP: desvio-padrão. RF: radiofrequência.

Dos 47 pacientes que foram submetidos ao DM, foi detectado aumento da TIE durante a abordagem da veia pulmonar superior esquerda (VPSE) em 18 deles (38\%), TIE máxima de $37,9^{\circ} \mathrm{C}$ e média de 37,03 com desvio-padrão (DP) de 0,58. A posição basal média do esôfago foi de $0,18 \mathrm{~cm}$ distante do cateter circular com 0,59 DP. Após o desvio mecânico, a TIE máxima foi de $36,5^{\circ} \mathrm{C}$, média de 35,92 com $0,65 \mathrm{DP}$, enquanto que o desvio mecânico máximo foi de 4,52 cm e o médio foi de 2,23 cm com 1,09 DP.

Em 15 pacientes (30\%), durante a abordagem da veia pulmonar inferior esquerda (VPIE) houve aumento da TIE, atingindo valor máximo de $37,6{ }^{\circ} \mathrm{C}$, média de 37,10 com 0,37 DP. A posição basal média do esôfago foi de $0,14 \mathrm{~cm}$ distante do cateter circular com 0,52 DP. Após o desvio mecânico, a TIE máxima foi de $36,3{ }^{\circ} \mathrm{C}$, média de 35,86 com $0,17 \mathrm{DP}$, enquanto que o desvio mecânico máximo foi de 3,5 cm e o médio foi de 2,03 com 1,09 DP.

Em 25 pacientes (55\%), durante a abordagem da veia pulmonar inferior direita (VPID) houve aumento da TIE, atingindo valor máximo de $38,1^{\circ} \mathrm{C}$, média de $36,94 \mathrm{com} 0,45 \mathrm{DP}$. A posição basal média do esôfago foi de $-0,10 \mathrm{~cm}$ distante do cateter circular com 0,56 DP. Após o desvio mecânico, a TIE máxima foi de $36,5^{\circ} \mathrm{C}$, média de 35,75 com $0,19 \mathrm{DP}$, enquanto que o desvio mecânico máximo foi de 5,27 cm e o médio foi de 2,22 com 1,0 DP.

Em 20 pacientes (44\%), durante a abordagem da veia pulmonar superior direita (VPSD) houve aumento da TIE, atingindo valor máximo de $38,6^{\circ} \mathrm{C}$, média de $37,01 \mathrm{com} 0,49 \mathrm{DP}$. A posição basal média do esôfago foi de $-0,08 \mathrm{~cm}$ distante do cateter circular com 0,53 DP. Após o desvio mecânico, a TIE máxima foi de $36^{\circ} \mathrm{C}$, média de 35,73 com $0,09 \mathrm{DP}$, enquanto que o desvio mecânico máximo foi de 6,17 e o médio foi de 2,35 com 1,25 DP. Na análise estatística em relação a amplitude do desvio mecânico, todos os valores apresentaram alto valor de significância estatística.

Com o objetivo de facilitar a visualização dos dados, a Tabela 3, Tabela 4 são relacionadas ao comportamento da TIE pré e pós-desvio mecânico. Enquanto que a Tabela 5 está relacionada à amplitude do desvio mecânico. 
Tabela 3 - Análise por VP da TIE $\left({ }^{\circ} \mathrm{C}\right)$ pré e pós-desvio mecânico.

\begin{tabular}{|c|c|c|}
\hline \multirow[t]{5}{*}{ VPSE $(n=18 / 47)$} & Temperatura média basal & $35,71 \pm 0,12$ \\
\hline & Temperatura máxima pré-desvio & 37,9 \\
\hline & Temperatura média pré-desvio & $37,03 \pm 0,58$ \\
\hline & Temperatura máxima pós-desvio & 36,5 \\
\hline & Temperatura média pós-desvio & $35,92 \pm 0,65$ \\
\hline \multirow[t]{5}{*}{ VPIE $(n=15 / 47)$} & Temperatura média basal & $35,71 \pm 0,12$ \\
\hline & Temperatura máxima pré-desvio & 37,6 \\
\hline & Temperatura média pré-desvio & $37,10 \pm 0,37$ \\
\hline & Temperatura máxima pós-desvio & 37,4 \\
\hline & Temperatura média pós-desvio & $35,86 \pm 0,17$ \\
\hline \multirow[t]{5}{*}{$\operatorname{VPSD}(n=20 / 47)$} & Temperatura média basal & $35,71 \pm 0,12$ \\
\hline & Temperatura máxima pré-desvio & 38,6 \\
\hline & Temperatura média pré-desvio & $37,01 \pm 0,49$ \\
\hline & Temperatura máxima pós-desvio & 36 \\
\hline & Temperatura média pós-desvio & $35,73 \pm 0,09$ \\
\hline \multirow[t]{5}{*}{ VPID $(n=25 / 47)$} & Temperatura média basal & $35,71 \pm 0,12$ \\
\hline & Temperatura máxima pré-desvio & 38,1 \\
\hline & Temperatura média pré-desvio & $36,94 \pm 0,45$ \\
\hline & Temperatura máxima pós-desvio & 36,5 \\
\hline & Temperatura média pós-desvio & $35,75 \pm 0,19$ \\
\hline
\end{tabular}


Gráfico 1 - Comportamento da temperatura de cada VP pré e pós-DM.s

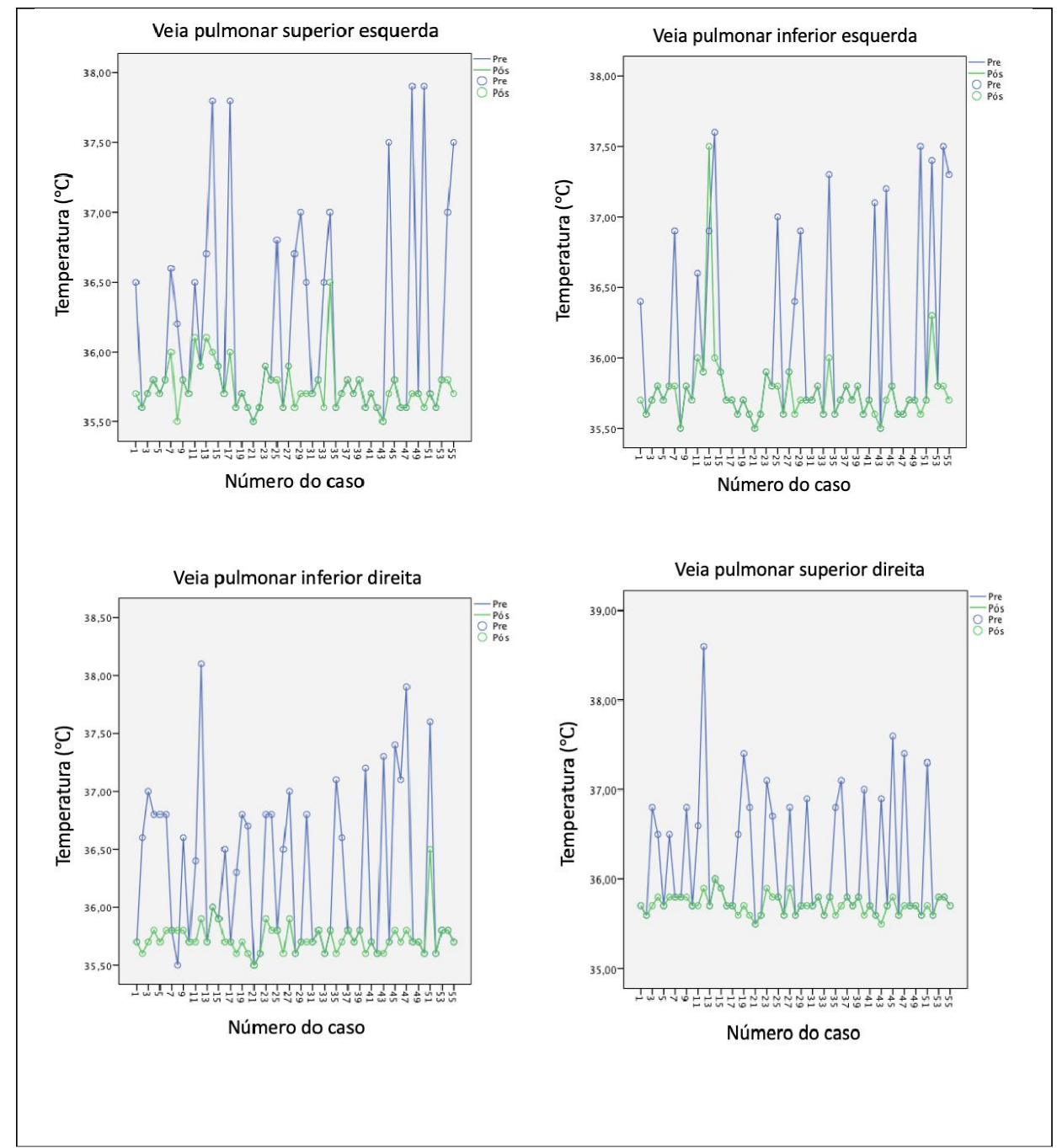

Tabela 4 - Análise estatística da TIE pré e pós-desvio mecânico $(\mathrm{p}<0,05)$.

\begin{tabular}{ll}
\hline Veia pulmonar superior esquerda & $<0,01$ \\
Veia pulmonar inferior esquerda & $<0,01$ \\
Veia pulmonar superior direita & $<0,01$ \\
Veia pulmonar inferior direita & $<0,01$ \\
Total & $<0,01$ \\
\hline
\end{tabular}


Tabela 5 - Análise da posição basal e amplitude pré e pós-desvio do esôfago (cm)

\begin{tabular}{lll}
\hline VPSE $(\mathbf{n = 1 8 / 4 7})$ & Basal média & $0,18 \pm 0,59$ \\
& Desvio mecânico médio & $2,23 \pm 1,09$ \\
& Desvio mecânico máximo & 4,52 \\
VPIE (n= 15/47) & Basal média & $0,14 \pm 0,52$ \\
& Desvio mecânico médio & $2,03 \pm 1,09$ \\
& Desvio mecânico máximo & 3,5 \\
VPSD (n= 20/47) & Basal média & $-0,08 \pm 0,53$ \\
& Desvio mecânico médio & $2,35 \pm 1,25$ \\
& Desvio mecânico máximo & 6,17 \\
\hline VPID $(\mathbf{n}=\mathbf{2 5 / 4 7})$ & Basal média & $-0,10 \pm 0,56$ \\
& Desvio mecânico médio & $2,22 \pm 1,0$ \\
& Desvio mecânico máximo & 5,27 \\
\hline
\end{tabular}

Do total de 47 pacientes que foram submetidos ao DM, 14(30\%) apresentaram sintomas sugestivos de lesão esofágica. Conforme o protocolo definido, estes 14 pacientes foram submetidos a endoscopia digestiva alta (EDA), sendo que o exame foi normal em 6 (43\%) deles. Foi identificado hematomas em 7(50\%) pacientes, sendo que os maiores diâmetros variaram de 0,3 a 10mm. Em 1(7\%) paciente, a imagem foi compatível com erosão superficial por trauma mecânico causado pelo tETE.

Os dados acima descritos mostram que o esôfago apresentou localização à direita mais frequente, que o DME foi necessário na maioria dos procedimentos realizados e obtido sucesso na prevenção do aumento da TIE $\geq 0,5^{\circ} \mathrm{C}$ em $87 \%$. O alcance médio do desvio foi de $2,25 \mathrm{~cm}$ e foi observada estabilidade da posição do esôfago após a realização do desvio em todos os casos. Os casos avaliados pela EDA demonstraram a presença de lesões discretas e superficiais as quais não exigiram qualquer tipo de intervenção, apenas observação clínica.

Portanto, os dados apresentados sugerem que o desvio mecânico é de grande valor na proteção do esôfago contra lesões térmicas durante o procedimento de ablação de FA. 


\section{LIMITAÇÕES}

A presença do termômetro esofágico, per se, não garante que a aplicação de RF seja completamente segura. $\mathrm{O}$ esôfago pode apresentar variados diâmetros, principalmente quando se encontra comprimido entre o AE e coluna vertebral, o que determina aumento do seu diâmetro látero-lateral, de forma que, não é possível assegurar a existência de sensores de temperatura em contato direto com a parede mais próxima do ponto aplicação de RF. Já a presença do tETE, juntamente com o termômetro, mas sem a realização do desvio mecânico, torna-se fator de risco por que o transdutor aproxima a parede anterior do esôfago para regiões mais próximas da parede posterior do AE (Figura 24).

Nesse caso, é mandatória a realização do desvio para um local distante do ponto de aplicação para que este recurso seja seguro e eficaz ou, ainda, caso o desvio não fosse realizado seria preferível retirar o tETE.

Nem sempre o termômetro acompanhará a rotação do tETE sobre o próprio eixo, manobra esta, necessária para promover a mudança do desvio para a direita ou a esquerda. Nestas situações, há a limitação da ausência do termômetro na parede ipsilateral ao ponto de aplicação de RF

Numa parcela menor de casos, o esôfago pode apresentar com menor mobilidade ou permitir o deslocamento unilateral apenas (Figura 25 e Figura 26).

E por último, para que possa ser utilizado o tETE para realizar o desvio mecânico, o paciente deve estar sob anestesia geral o que não é rotina em todos os serviços de eletrofisiologia.

Figura 24 - Transdutor do ETE.

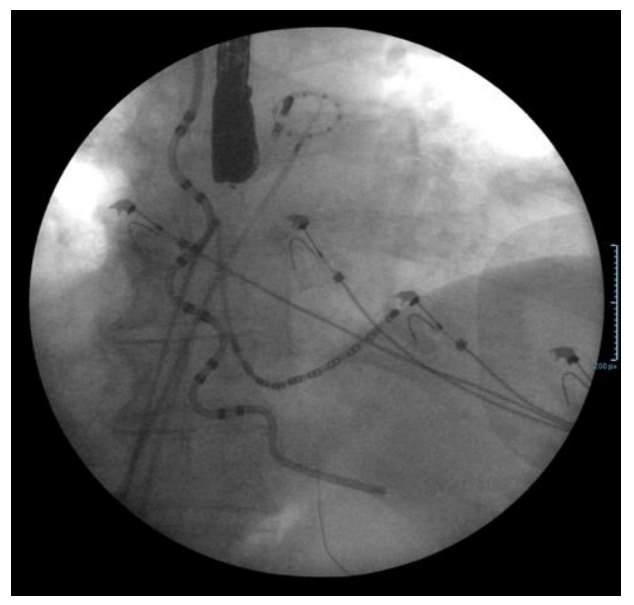


A importância de que seja sempre realizado o desvio mecânico na presença do ETE ao nível do coração, pois, este promove o deslocamento da parede anterior do esôfago para regiões ainda mais próximas da parede posterior do AE.

Figura 25 - Diferentes amplitudes de desvio.
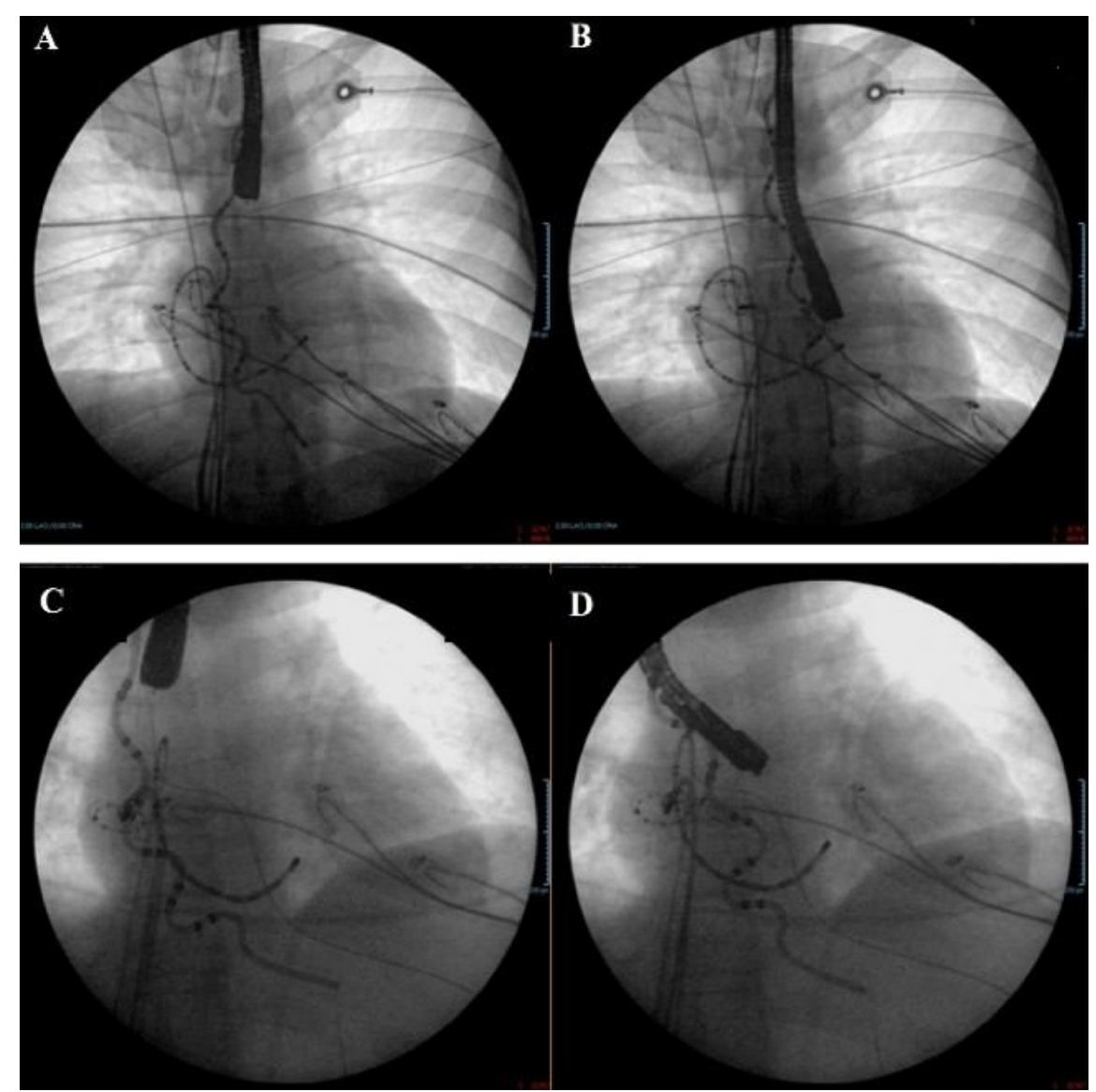

A e B) Desvio mecânico com adequada amplitude. C e D) Desvio mecânico com amplitude reduzida. 
Figura 26 - Desvio unilateral.

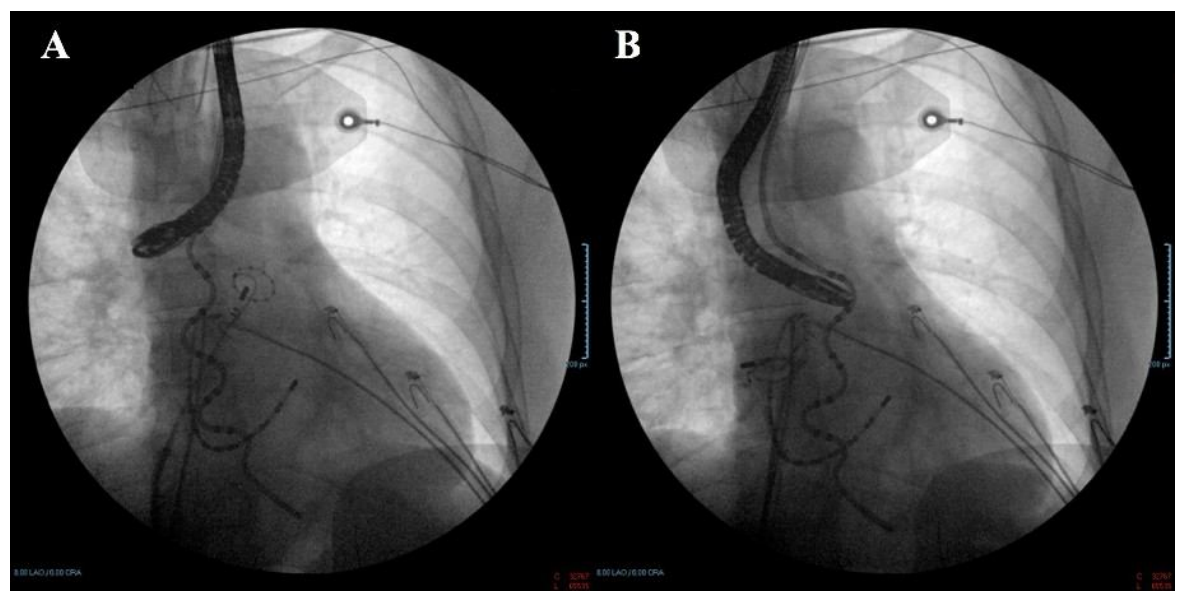

A) Mínimo grau de desvio para a direita. B) Desvio adequado para a esquerda, bem representado pela curva vista no termômetro intra-esofágico. $\mathrm{O}$ esôfago pode apresentar o desvio preferencialmente unilateral. 


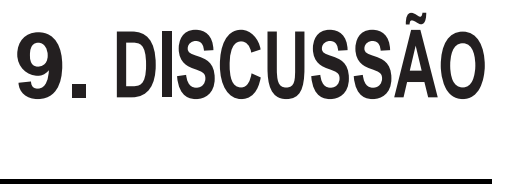




\section{DISCUSSÃO}

O tratamento da FA por cateter continua a crescer e, atualmente, apresenta-se como a alternativa terapêutica mais eficaz na manutenção do ritmo sinusal, melhora da qualidade de vida e, até mesmo, da função ventricular esquerda ${ }^{7,8,10,11}$. No entanto, potenciais complicações são inerentes a qualquer procedimento invasivo.

Diversos estudos confirmaram a importância da realização do isolamento elétrico das VPs para obtenção de maior sucesso do procedimento de ablação da FA ${ }^{11,12}$. A RF aplicada na parede posterior do AE pode ser transmitida pelos tecidos e determinar o aquecimento do esôfago, pois, estas duas estruturas possuem relação anatômica muito próxima, 1,9 \pm 0,7 mm de distância média entre elas e um diâmetro transverso médio de contato (sobreposição) de 18,9 $\pm 4,4 \mathrm{~mm}^{25}$.

A organização anatômica do esôfago apresenta uma grande concentração de artérias e plexos vagais na sua parede anterior, especialmente ao nível da adventícia. Desta maneira, agressões térmicas oriundas da parede posterior do AE poderão comprometê-las mesmo sem alterações evidentes na EDA. E, como consequência desta relação anatômica tão próxima, são descritas complicações tais como, erosão e/ou úlcera da mucosa, gastroparesia e, mais raramente, a fístula atrioesofágica, a complicação mais temida por sua maior gravidade ${ }^{34}$.

O mecanismo fisiopatológico da formação da FAE é baseado na lesão térmica causada pela RF. Este é composto pelo comprometimento do suprimento sanguíneo arterial, devido à oclusão de arteríolas terminais, da lesão do plexo vagal anterior, que irá promover maior refluxo do conteúdo ácido gástrico para o esôfago devido ao comprometimento da contratilidade do antro gástrico e do esfíncter esofagiano inferior, e por possíveis infecções do lúmen esofágico 33,34,42. Além disso, a ulceração esofágica aparenta ser a lesão precursora para a formação da FAE. Isso decorre da observação de que não há relatos de necrose, nem de perfuração atrial na ausência de lesão esofágica, enquanto que a lesão isolada do esôfago é bem reconhecida ${ }^{34}$.

Em publicação recente e, pela primeira vez, foi demonstrada a correlação direta entre lesão térmica do esôfago pós-ablação detectada por EDA e perfuração esofágica. Dos pacientes que apresentaram erosão, nenhum evoluiu com perfuração, enquanto que, $10 \%$ dos que apresentaram úlcera no pós-procedimento evoluíram com perfuração esofágica. Assim, a lesão térmica seria um pré-requisito para o desencadeamento da cascata de eventos que podem determinar o surgimento da FAE. E aumentos na TIE $>40,5^{\circ} \mathrm{C}$, estariam associados à aumento em 2,1 vezes no risco de lesões térmicas. 
Os primeiros registros de FAE relacionados à ablação da FA com cateter por RF foram descritos em $2004^{73,74}$. No entanto, apesar ter ocorrido uma importante evolução dos sistemas de mapeamento, cateteres, fontes de energia, determinando a redução de outras complicações, a FAE ainda é motivo de preocupação pelo seu alto potencial de letalidade ${ }^{42}$. Desta forma, diversas técnicas foram desenvolvidas com o intuito de prevenir a aplicação de RF nas regiões adjacentes ao esôfago devido aos riscos comentados acima. Para isso, a delimitação das bordas laterais e do trajeto do esôfago são fundamentais. Deve-se sempre levar em consideração que o esôfago é um órgão complexo, móvel, pouco aderido as estruturas próximas e apresenta peristalse frequente. Como consequência, as técnicas que não têm a capacidade de atualizar em tempo real a posição do esôfago, podem levar a equívocos sobre o seu trajeto e aumento do risco de lesões térmicas.

O uso do bário, como meio de contraste, e do EIC, permitem acompanhar as modificações do trajeto do esôfago em tempo real, enquanto que o EIC permite integrar a sua imagem com o sistema de mapeamento eletroanatômico 3D, além de informar a distância entre o esôfago e AE e, também, a área de contato entre as duas estruturas. A utilização de outros métodos de imagem como a TC ou RNM também permitem a integração das suas imagens com os sistemas de mapeamento eletroanatômico 3D. No entanto, os dois últimos métodos, possuem a limitação de produzirem imagens estáticas, ou seja, não atualizam a posição do esôfago em tempo real.

Outras abordagens causam interesse por terem como base o resfriamento do esôfago através da instilação de soro gelado ou por meio de um balão de resfriamento. Entretanto, nenhuma apresentou resultados consistentes na prevenção de complicações esofágicas por aquecimento. Além do mais, o balão de resfriamento, quando expandido, desloca a parede anterior do esôfago em direção ao AE, aumentando o risco de lesões térmicas. É importante ser ressaltado que esses procedimentos visam a proteção do esôfago por meio de um resfriamento da região intra-luminal inicialmente, ou seja, da mucosa em direção à adventícia. Enquanto que o aquecimento, proveniente do cateter de RF, ocorre no sentido inverso. Desta maneira, o resfriamento pode não ser suficiente para reduzir a temperatura das camadas mais externas e, por conseguinte, prevenir tais complicações ${ }^{64,65}$.

Em havendo o propósito de maior controle sobre as variações da TIE durante o procedimento de ablação de FA, um termômetro esofágico pode ser utilizado. No entanto, a sua presença pode gerar uma falsa sensação de segurança porque nem sempre este dispositivo está em contato direto com a parede que apresenta risco de aquecimento. Estes dispositivos evoluíram de formas lineares para um formato senoidal e, com isso, dispõem de maior 
sensibilidade para detectar variações da TIE por abrangerem uma área maior. Também, deve ser levado em consideração o fenômeno de latência de aquecimento, que ocorre entre a camada externa do esôfago até a mucosa, onde está localizado o termômetro, ou seja, até que haja o aquecimento da mucosa, as camadas externas experimentam temperaturas mais elevadas.

Uma vez identificada a elevação da TIE acima do limite determinado, uma forma de abordagem seria a não aplicação da RF neste ponto e ter como consequência o possível não isolamento da VP ou a não abordagem de regiões que, muitas vezes, são fundamentais para o completo procedimento de ablação. De todas as técnicas já citadas, apesar de serem capazes de identificar o problema do aquecimento ou da sobreposição entre esôfago e região de aplicação de RF, nenhuma delas é capaz de modificar a posição deste órgão quando está em uma localização de risco de aquecimento.

Com o objetivo de oferecer maior segurança e eficácia no procedimento de ablação de FA, a técnica desenvolvida no SEMAP-HCor e avaliada neste estudo foi utilizar o tETE, que rotineiramente faz parte do procedimento, para promover o desvio mecânico do esôfago. Esta técnica tem, dentre outros, o benefício de não adicionar gasto relacionado ao procedimento e, também, de já ter a sua segurança testada em diversos estudos que avaliaram os riscos da manipulação do esôfago pelo tETE. Estes estudos demonstraram taxas de complicações semelhantes à $\operatorname{EDA}^{75,76}$.

A utilização de anestesia geral para realizar o procedimento de ablação de FA é fundamental para que esta técnica possa ser aplicada com conforto tanto para a equipe médica e, principalmente, para o paciente. Inicialmente, o transdutor é introduzido e posicionado pelo anestesista e notamos que quanto maior a experiência deste profissional, maior a facilidade na inserção do dispositivo. Não foram observadas complicações com repercussão clínica relacionadas ao manuseio do tETE e, em todos os casos, a passagem e o posicionamento adequado do dispositivo no esôfago foi possível. Quanto à redução da peristalse, que está relacionada à anestesia geral ${ }^{34}$, não é motivo de preocupação, pois, o esôfago será deslocado mecanicamente da região de risco e não dependerá de mecanismos peristálticos intrínsecos para se proteger de possíveis agressões térmicas.

No entanto, a simples presença do tETE no lúmen esofágico é considerada fator de risco, pois, é capaz de projetar o esôfago em direção da parede posterior do AE. Desta forma, é mandatória a realização do desvio mecânico para um ponto contra-lateral, distante da aplicação de RF. Além disso, com o objetivo de aumentar o nível de segurança da técnica, utilizamos em todos os casos um termômetro esofágico multicanal para monitorar a TIE. 
Por não haver um posicionamento unânime se existe um valor máximo de temperatura do esôfago que seja seguro para evitar lesões térmicas, optamos por aumentar o rigor e o nível de segurança neste estudo. Assim, foi determinado que na elevação da TIE $\geq 0,5^{\circ} \mathrm{C}$, a aplicação de RF seria imediatamente suspensa. Não encontramos um grau tão alto de sensibilidade na variação da TIE em outras publicações até o momento já que estas consideram aumentos $>1{ }^{\circ} \mathrm{C}$ em relação a temperatura basal ou valores absolutos a partir de $38,5^{\circ} \mathrm{C}^{33}$. Além disso, foi observado o fenômeno de latência de aquecimento, ou seja, mesmo após a suspensão da aplicação de RF, a temperatura do esôfago pode continuar a aumentar atingindo valores próximos a $1^{\circ} \mathrm{C}$.

Os autores Sternick et al., e Müller et al. levantaram a questão de um possível efeito por indução (efeito antena) que poderia ocorrer entre a ponta do cateter de RF e os pólos de temperatura metálicos do termômetro que determinaria lesões esofágicas. Como fator de risco independente na análise de regressão logística, este dispositivo apresentou um odds ratio de $16,7, \mathrm{p}<0,01^{61,62}$. No entanto, o termômetro utilizado não apresentava isolamento nos polos metálicos de temperatura. Na sequência, foi analisado o risco de lesão esofágica utilizando termômetros com isolamento elétrico nos polos de temperatura. A incidência de lesões esofágicas foi semelhante no grupo com a utilização e no grupo sem a utilização do dispositivo, respectivamente $(7,5 \% \text { vs. } 10 \%, \mathrm{p}=1,0)^{63}$. Portanto, o entendimento atual para o uso de termômetros com isolamento elétrico dos seus polos de temperatura é que eles adicionam segurança ao procedimento de ablação ${ }^{77}$. Já Pérez et al., utilizando um modelo computacional, não demonstraram o efeito antena com a utilização de um termômetro com isolamento elétrico $^{78}$.

Apesar da literatura descrever maior prevalência da posição basal do esôfago próximo às veias pulmonares esquerdas ${ }^{24,25}$, na nossa observação, a posição basal mais frequente foi próxima às veias pulmonares direitas (45\%). Na grande maioria dos casos (85\%), foi necessário o deslocamento do esôfago para regiões distantes por haver aquecimento durante a aplicação de RF com esôfago em posição basal, sendo que em $87 \%$ destes deslocamentos, foi possível evitar aumentos de temperatura $\geq 0,5^{\circ} \mathrm{C}$. Se for considerado apenas o critério de aumento da TIE $\geq 38,5^{\circ} \mathrm{C}$, o nosso sucesso foi de $100 \%$.

O esôfago apresentou estabilidade após ser submetido ao desvio em todos os casos, ou seja, manteve-se na mesma posição durante todo o tempo necessário para a aplicação de RF. Além disso, o deslocamento médio de 2,25 $\pm 1,19 \mathrm{~cm}$ foi suficiente para permitir que as 
aplicações de RF apresentassem valores da TIE muito semelhantes aos valores basais. No seguimento de até 3 meses, não foi identificada qualquer complicação relacionada ao esôfago. 


\section{CONCLUSÃO}

1. Os resultados deste estudo sugerem que o desvio mecânico do esôfago evita o aumento de temperatura deste órgão durante a ablação de FA por cateter com RF. Desta forma, constitui-se num recurso valioso, pois, permite que o isolamento das veias pulmonares, a realização de linhas de bloqueio na parede posterior do átrio esquerdo, a ablação dos ninhos de FA e a ablação de taquicardias atriais em qualquer parte das paredes atriais sejam realizados com maior liberdade e eficácia, sem necessidade de limitar, interromper ou reduzir a aplicação de RF. O deslocamento do esôfago da região alvo da RF, é uma alternativa simples, eficaz, segura e de baixo custo contra possíveis efeitos deletérios que o aquecimento possa gerar, detectáveis ou não pela endoscopia digestiva alta.

2. A amplitude do deslocamento esofágico obtido foi suficiente para evitar o aquecimento do lúmen do esôfago em $87 \%$ dos casos, considerando o aumento de temperatura $<0,5^{\circ} \mathrm{C}$, e evitou que a temperatura luminal esofágica fosse igual ou além de $38,5^{\circ} \mathrm{C}$ em $100 \%$ dos casos.

3. Além do desvio, a técnica descrita mostrou-se eficaz em estabilidade, mantendo o deslocamento do esôfago ao longo do procedimento de forma segura. 


\section{CRONOGRAMA DE EXECUÇÃO}

\begin{tabular}{|c|c|c|c|c|c|c|c|c|}
\hline Itens & $\begin{array}{l}\text { Fev - } \\
\text { Jun } \\
2015\end{array}$ & $\begin{array}{l}\text { Jul - } \\
\text { Dez } \\
2015\end{array}$ & $\begin{array}{l}\text { Jan - } \\
\text { Jun } \\
2016\end{array}$ & $\begin{array}{l}\text { Jul - } \\
\text { Dez } \\
2016\end{array}$ & $\begin{array}{l}\text { Jan - } \\
\text { Jun } \\
2017\end{array}$ & $\begin{array}{l}\text { Jun - } \\
\text { Dez } \\
2017\end{array}$ & $\begin{array}{l}\text { Jan - } \\
\text { Jun } \\
2018\end{array}$ & $\begin{array}{l}\text { Jul - } \\
\text { Dez } \\
2018\end{array}$ \\
\hline $\begin{array}{l}\text { Curso das } \\
\text { Disciplinas } \\
\text { Obrigatórias }\end{array}$ & $X$ & $X$ & $X$ & & & & & \\
\hline $\begin{array}{l}\text { Levantamento } \\
\text { bibliográfico }\end{array}$ & $\mathrm{X}$ & $\mathrm{X}$ & $X$ & $X$ & $X$ & & & \\
\hline $\begin{array}{l}\text { Seleção dos } \\
\text { pacientes para } \\
\text { ablação de FA }\end{array}$ & $X$ & $X$ & & & & & & \\
\hline \begin{tabular}{ll}
\multicolumn{2}{l}{ Avaliação da } \\
eficácia da \\
técnica de \\
desvio do \\
esôfago
\end{tabular} & $X$ & $X$ & $X$ & & & & & \\
\hline $\begin{array}{l}\text { Elaboração do } \\
\text { trabalho para } \\
\text { qualificação } \\
\text { da tese }\end{array}$ & $X$ & $X$ & $X$ & $X$ & & & & \\
\hline $\begin{array}{l}\text { Elaboração do } \\
\text { trabalho final }\end{array}$ & & & $X$ & $X$ & $X$ & $X$ & $X$ & $X$ \\
\hline
\end{tabular}


12. ANEXOS 
12. ANEXOS

\subsection{APÊNDICE A - TERMO DE CONSENTIMENTO LIVRE E ESCLARECIDO}

CENTRO:

INVESTIGADOR: Dr. Ricardo Carneiro Amarante

ORIENTADOR: Prof. Dr. José Carlos Pachón Mateos

PACIENTE (INICIAIS / NÚMERO):

EFICÁCIA DA TÉCNICA DO DESVIO MECÂNICO NA PREVENÇÃO DO AQUECIMENTO DO ESÔFAGO NA ABLAÇÃO DA FIBRILAÇÃO ATRIAL COM CATÉTER POR RADIOFREQUÊNCIA

\section{OBJETIVO DO ESTUDO}

O(A) senhor(a) está sendo convidado(a) para participar deste estudo, pois, apresenta indicação de ablação da fibrilação atrial por cateter de radiofrequência. Os sintomas apresentados pela sua doença podem ser diminuídos através da ablação, técnica há muito tempo tida como opção para o tratamento desta arritmia.

\section{PROCEDIMENTOS DO ESTUDO}

Caso o(a) senhor(a) deseje participar deste estudo que compreende a realização da ablação da fibrilação atrial conforme o procedimento de rotina do setor de arritmias da SEMAP/HCor que se dá através de anestesia, colocação de placas adesivas no tórax para obtenção do sinal do coração, passagem de cateteres por punção (sem corte) para a realização do mapeamento dos focos das arritmias e tratamento (ablação), passagem da sonda do ecocardiograma transesofágico para avaliação do coração e do termômetro esofágico para monitorização da temperatura durante a ablação (aplicação de energia). Neste caso, não há nenhum risco adicional para o procedimento em questão. 


\section{RISCOS}

Os riscos do presente estudo estão relacionados ao procedimento em si, tais como alergias a medicações, arritmias cardíacas e complicações cardioembólicas (acidente vascular cerebral). Contudo, a participação neste estudo não submete o(a) senhor(a) a riscos adicionais ao procedimento, que estaria indicado independentemente da participação neste estudo.

\section{BENEFÍCIOS POTENCIAIS}

A ablação da fibrilação atrial utilizando a técnica de desvio do esôfago, permite aumentar o grau de segurança do procedimento. Assim, potenciais complicações relacionadas ao aumento de temperatura do esôfago poderão ser evitadas. O objetivo deste estudo é simplesmente detectar qualquer aumento de temperatura do esôfago precocemente, evitando potenciais lesões.

\section{ALTERNATIVA A PARTICIPAÇÃO}

Caso o(a) senhor(a) não deseje participar do presente estudo, o tratamento para sua doença será fornecido da mesma forma e sem nenhum prejuízo ao(à) senhor(a), sendo realizada a ablação seguindo a técnica padrão do serviço de arritmias SEMAP/HCor.

\section{CONFIDENCIALIDADE}

Se for do desejo do(a) senhor(a) participar deste estudo, todos os seus registros médicos (exames e avaliações) serão conferidos pela equipe médica da pesquisa com a finalidade de fornecer dados para a realização do estudo. Os dados registrados no prontuário do(a) senhor(a) podem ser solicitados pelas autoridades regulatórias e comitês de ética em pesquisa para conferir se o presente estudo está sendo realizado segundo as diretrizes de ética em pesquisa para seres humanos.

Uma vez que o(a) senhor(a) assine este Termo de Consentimento Livre e Esclarecido, o(a) senhor(a) está dando permissão para sua participação no mesmo. Sua identidade será mantida em sigilo quando os resultados deste estudo forem publicados, uma vez que apenas os dados referentes à sua doença e tratamento serão divulgados. 
As informações geradas por seus exames e avaliações serão armazenadas em um computador onde não serão permitidos acessos de pessoas além da equipe de pesquisa.

\section{NOVOS ACHADOS}

Se durante a realização do estudo surgirem quaisquer achados clínicos relevantes que possam alterar seu desejo de participar na pesquisa o(a) senhor(a) será prontamente informado(a).

\section{PARTICIPAÇÃO VOLUNTÁRIA E CONSENTIMENTO}

A participação do(a) senhor(a) no presente estudo é voluntária, ou seja, o(a) senhor(a) não receberá nenhuma quantia em dinheiro para participação neste estudo.

A qualquer momento o(a) senhor(a) poderá se recusar a continuar na pesquisa sem precisar dar nenhuma explicação e sem nenhum prejuízo ao seu acompanhamento ou tratamento.

\section{TRATAMENTO MÉDICO/INDENIZAÇÃO}

Em relação a qualquer dano direto ou indireto causado pelo presente estudo clínico, o Dr. Ricardo Carneiro Amarante assume a responsabilidade por lei por tais danos, desde que:

- Fique determinado que o dano causado está relacionado com os procedimentos deste estudo;

- Todas as pessoas e instituições envolvidas tenham seguido as exigências do estudo;

- A equipe médica tenha agido de acordo com a prática científica e técnicas e conhecimentos atualmente aceitos.

Ao assinar esse termo o(a) senhor(a) não abre mão de nenhum direito legal.

\section{SOLICITAÇÃO DE INFORMAÇÕES ADICIONAIS}

Em caso de alguma dúvida a respeito de qualquer aspecto da pesquisa, o(a) senhor(a) pode entrar em contato com o Dr. Ricardo Carneiro Amarante imediatamente através do telefone (11) 3053-6611, Ramal: 4500 ou pelo celular (11) 98340-7078. Ainda, o(a) senhor(a) poderá entrar em contato com o Comitê em Ética em Pesquisa do Instituto Dante Pazzanese de 
Cardiologia (IDPC) no telefone (11) 3053-6611, Ramal: 8458 para o esclarecimento de alguma dúvida relativa aos seus direitos em relação à sua participação no estudo.

Uma cópia deste termo lhe será entregue.

Desta forma, declaro que li e compreendi este termo de consentimento e todas as minhas possíveis dúvidas foram esclarecidas. Recebi explicações sobre o objetivo da pesquisa e sobre os procedimentos relacionados. As alternativas à minha participação na pesquisa também foram esclarecidas. Assim sendo, concordo voluntariamente em fornecer o meu consentimento para participar deste estudo.

Paciente:

RG: Data: Hora:

Assinatura:

Testemunha:

RG: Data: Hora:

Assinatura:

Assinatura do Investigador: Data: Hora: 
12.2 APÊNDICE B - Exames de imagem.

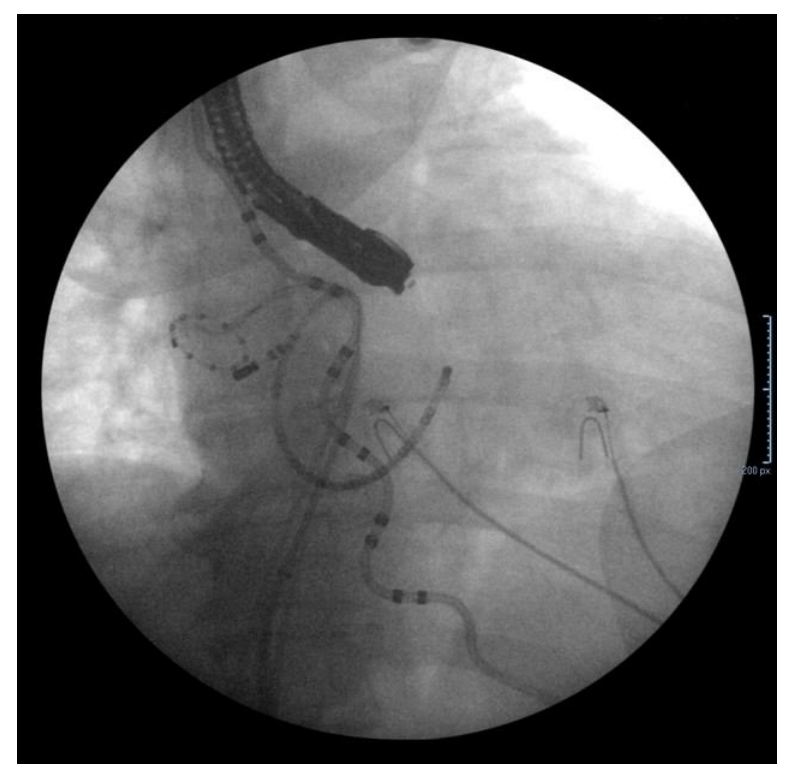

Figura 27 - Desvio mecânico.

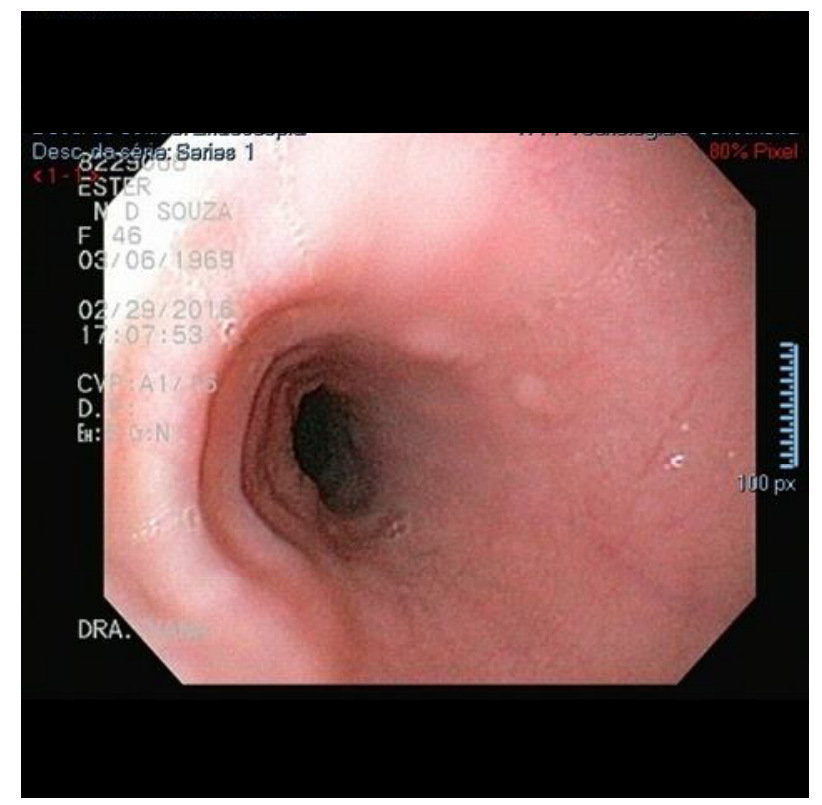

Figura 28 - EDA 1 . O corpo do esôfago não apresenta qualquer evidência de lesão ou trauma. 


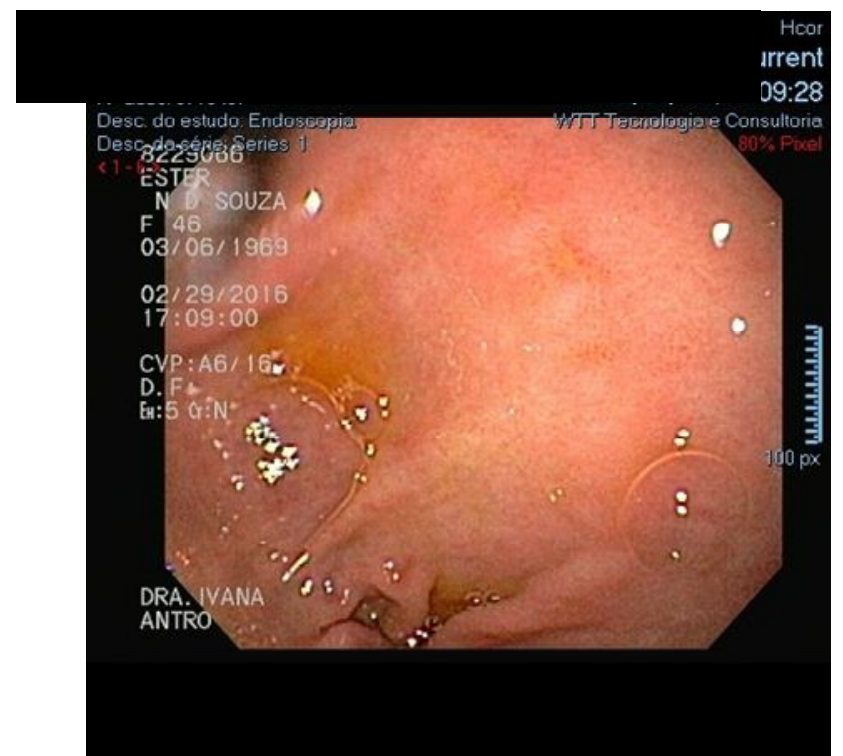

Figura 29 - EDA 2. Gastrite erosiva discreta em região antral.

\section{ENDOSCOPIA DIGESTIVA ALTA}

\section{Esôfago:}

Com calibre, mucosa e distensibilidade preservados. Trajeto retilíneo. A TEG se encontra coincidente com o pinçamento diafragmático.

\section{Estômago:}

Volume, forma e distensibilidade preservados. Lago mucoso claro em quantidade regular. $\mathrm{O}$ pregueado do fundo e corpo é uniforme. Incisura angula está íntegra. Antro apresentando algumas erosões planas. Piloro centrado, pérvio e sem deformidades.

\section{Duodeno:}

Bulbo duodenal distensível apresentando mucosa sem lesões. A $2^{\mathrm{a}}$ porção duodenal tem mucosa preservada.

\section{Conclusão:}

1) Gastrite erosiva discreta de antro. 


\section{REFERÊNCIAS BIBLIOGRÁFICAS}

${ }^{1}$ Braunwald, E. Tratado de Doenças Cardiovasculares. 7 ed. Rio de Janeiro: Elsevier; 2006. p. 869-870.

${ }^{2}$ Wolf PA, et al. Secular trends in the prevalence of atrial fibrillation: The Framingham Study. Am Heart J. 1996;131:790-5.

${ }^{3}$ Kannel WB, et al. Prevalence, incidence, prognosis, and predisposing conditions for atrial fibrillation: population-based estimates. Am J Cardiol. 1998;82:2-9.

${ }^{4}$ Miller PS, Andersson FL, Kalra L. Are cost benefits of anticoagulation for stroke prevention in atrial fibrillation underestimated? Stroke. 2005;36:360-6.

${ }^{5}$ Wang TJ, et al. Temporal relations of atrial fibrillation and congestive heart failure and their joint influence on mortality: the Framingham Heart Study. Circulation. 2003;107:2920-5.

${ }^{6}$ Ott A, et al. Atrial fibrillation and dementia in a population-based study. The Rotterdam Study. Stroke. 1997;28:316-21.

${ }^{7}$ Wilber DJ, et al. Comparison of antiarrhythmic drug therapy and radiofrequency catheter ablation in patients with paroxysmal atrial fibrillation: a randomized controlled trial. ThermoCool AF Trial Investigators JAMA. 2010;303(4):333.

${ }^{8}$ Hunter RJ, et al. A Randomized Controlled Trial of Catheter Ablation Versus Medical Treatment of Atrial Fibrillation in Heart Failure (The CAMTAF Trial). Circ Arrhythm Electrophysiol. 2014;7:31-38.

${ }^{9}$ LOBO TJ, et al. Ablação da Fibrilação Atrial na Disfunção Sistólica: Evolução Clínica e Ecocardiográfica. Arq. Bras. Cardiol. 2015;104(1):45-52.

${ }^{10}$ Marrouche NF, et al. CASTLE-AF Investigators. Catheter ablation for atrial fibrillation with

heart failure. N Engl J Med. 2018;378(5):417-27.

${ }^{11}$ Pappone C, et al. A Randomized Trial of Circumferential Pulmonary Vein Ablation Versus Antiarrhythmic Drug Therapy in Paroxysmal Atrial Fibrillation - The APAF Study. J Am Coll Cardiol 2006;48:2340-7.

${ }^{12}$ Haissaguerre M, et al. Spontaneous initiation of atrial fibrillation by ectopic beats originating in the pulmonary veins. N Engl J Med. 1998;339(10):659-66.

${ }^{13} \mathrm{Li} \mathrm{WJ}$, et al. Additional ablation of complex fractionated atrial electrograms (CFAEs) after pulmonary vein isolation (PVAI) in patients with atrial fibrillation: a meta-analysis. Circ Arrhythm Electrophysiol. 2011;4:143-148.

${ }^{14}$ Knetch S, Hocini M, Wright M. Left atrial linear lesions are required for successful treatment of persistent atrial fibrillation. European Heart Journal. 2008;29:2359-2366.

15 Pachón JC, et al. "AF Nests" electrical resonance. Is it a new atrial fibrillation physiopathology? Heart Rhythm. 2005;2(5):149.

${ }^{16}$ Pachón JC, et al. Ablação da fibrilação atrial por cateter com radiofrequência guiada por mapeamento espectral endocárdico dos "ninhos de FA" em ritmo sinusal. Arq Bras Cardiol. 2007;89(3):140-150.

17 Mateos JCP, et al. Ablation of "Background Tachycardia" in Long Standing Atrial Fibrillation: Improving the Outcomes by Unmasking a Residual Atrial Fibrillation Perpetuator. J Atr Fibrillation. 2017;10(2):1583.

${ }^{18}$ Vijayaraman P, Netrebko P, Geyfman V. Esophageal fistula formation despite esophageal monitoring and low-power radiofrequency catheter ablation for atrial fibrillation. Circ Arrhythmia Electrophysiol. 2009;2:31-33.

${ }^{19}$ Teplitsky L, et al. Radiofrequency catheter ablation for atrial fibrillation produces delayed and long lasting elevation of luminal esophageal temperature independent of lesion duration and power. Heart Rhythm. 2005;2(5):S8-S9. 
${ }^{20}$ Kuck KH, et al. Impact of Complete Versus Incomplete Circumferential Lines Around the Pulmonary Veins During Catheter Ablation of Paroxysmal Atrial Fibrillation. Circ Arrhythm Electrophysiol. 2016;9(1):e003337.

${ }^{21}$ Ho Y, Ernst S. Anatomy for Cardiac Electrophysiologists. A Practical Handbook. 1a. Ed. Minneapolis. Cardiotext. p. 11-12.

${ }^{22}$ Moore KL. Anatomia Orientada para a Prática Clínica. 4ª ed. Rio de Janeiro: Guanabara Koogan, 2001. p. 133-194.

${ }^{23}$ Jang SW, et al. Computed tomographic analysis of the esophagus, left atrium, and pulmonary veins: implications for catheter ablation of atrial fibrillation. J Interv Card Electrophysiol. 2011;32:1-6.

${ }^{24}$ Maeda S, et al. Complex anatomy surrounding the left atrial posterior wall: analysis with3D computed tomography. Heart Vessels. 2012;27:58-64.

${ }^{25}$ Cury RC, Abbara S, Schmit S. Relationship of the esophagus and aorta to the left atrium and pulmonary veins: Implications for catheter ablation of atrial fibrillation. Heart Rhythm 2005;2:1317-1323.

${ }^{26}$ Bahnson TD. Strategies to Minimize the Risk of Esophageal Injury During Catheter Ablation for Atrial Fibrillation. Pacing Clin Electrophysiol. 2009;32(2):248-260.

${ }^{27}$ Netter, Frank H. Atlas de anatomia humana. 2a . ed. Porto Alegre: Artmed, 2000. p. 220.

${ }^{28}$ Sánchez-Quintana D, et al. Anatomic relations between the esophagus and left atrium and rele- vance for ablation of atrial fibrillation. Circulation. 2005;112:1400-1405.

${ }^{29}$ Linz D, et al. Atrial fibrillation and gastroesophageal reflux disease: the cardiogastric interaction. Europace. 2016;19(1):16-20.

${ }^{30}$ Gerstenfeld EP, et al. Characteristics of patients undergoing atrial fibrillation ablation: trends over a seven-year period 1999- 2005. J Cardiovasc Electrophysiol. 2007;18:23-28.

${ }^{31}$ Nair KKM, et al. Atrioesophageal Fistula: A Review. Journal of Atrial Fibrillation 2015;8(3):79-83.

${ }^{32}$ Martinek M, et al. Esophageal damage during radiofrequency ablation of atrial fibrillation: impact of energy settings, lesion sets, and esophageal visualization. J Cardiovasc Electrophysiol 2009;7:726-733.

${ }^{33}$ Scanavacca, M. Ablação de FA e risco de lesão esofágica. Arq Bras Cardiol. 2016; 106(5):354-357.

${ }^{34}$ Kapur S, et al. Esophageal Injury and Atrioesophageal Fistula Caused by Ablation for Atrial Fibrillation. Circulation. 2017;136:1247-1255.

35 John RM, et al. Atrioesophageal fistula formation with cryoballoon ablation is most commonly related to the left inferior pulmonary vein. Heart Rhythm. 2016. 14(2):184-189.

${ }^{36}$ Yokoyama K, Nakagawa H, Seres KA. Canine Model of Esophageal Injury and AtrialEsophageal Fistula After Applications of Forward-Firing High-Intensity Focused Ultrasound and Side-Firing Unfocused Ultrasound in the Left Atrium and Inside the Pulmonary Vein. Circ Arrhythmia Electrophysiol. 2009;2:41-49.

${ }^{37}$ Kottkamp H, et al. Specific linear left atrial ablation in atrial fibrillation. J Am Coll Cardiol. 2002;40(3):475- 80.

${ }^{38}$ Tilz RR, et al. Unexpected high incidence of esophageal injury following pulmonary vein isolation using robotic navigation. J Cardiovasc Electrophysiol. 2010;21:853-858.

${ }^{39}$ Halbfass P, et al. Progression From Esophageal Thermal Asymptomatic Lesion to Perforation Complicating Atrial Fibrillation Ablation A Single-Center Registry. CircArrhythm Electrophysiol. 2017;10:e005233.

${ }^{40} \mathrm{Schmidt} \mathrm{M}$, et al: Incidence of oesophageal wall injury post-pulmonary vein antrum isolation for treatment of patients with atrial fibrillation. Europace. 2008;10(2):205-209. 
${ }^{41}$ Cappato $\mathrm{R}$, et al. Prevalence and causes of fatal outcome in catheter ablation of atrial fibrillation. J Am Coll Cardiol. 2009;53:1798-1803.

${ }^{42}$ Vasconcelos JTM, Filho SSG, Atié J. Atrial-oesophageal fistula following percutaneous radiofrequency catheter ablation of atrial fibrillation: the risk still persists. Europace. 2017;19(2):250-258.

${ }^{43}$ Nair GM, Nery PB, Lam BK. Atrioesophageal Fistula in the Era of Atrial Fibrillation Ablation: A Review. Canadian Journal of Cardiology. 2014;30(4):388-395.

${ }^{44}$ Han HC, et al. Atrioesophageal Fistula Clinical Presentation, Procedural Characteristics, Diagnostic Investigations, and Treatment Outcomes. Circ Arrhythm Electrophysiol. 2017;10(11):e005579.

${ }^{45}$ Garg L, et al. Gastrointestinal complications associated with catheter ablation for atrial fibrillation. International Journal of Cardiology. 2016;224:424-430.

${ }^{46}$ Wang H, Liu Q, Song Y. Severe gastroparesis after catheter ablation of atrial fibrillation: A case report and review of the literature. Exp Clin Cardiol 2013.

${ }^{47}$ Malamis AP, Kirshenbaum KJ, Nadimpalli S. CT radiographic findings: atrio-esophageal fistula after transcatheter percutaneous ablation of atrial fibrillation. $J$ Thorac Imaging. 2007;22(2):188-91.

${ }^{48}$ Chavez PD, Messerli FH, Dominguez AC. Atrioesophageal fistula following ablation procedures for atrial fibrillation: systematic review of case reports. Open Heart. 2015;2:e000257.

${ }^{49}$ Singh SM, et al. Clinical outcomes after repair of left atrial esophageal fistulas occurring after atrial fibrillation ablation procedures. Heart Rhythm. 2013;10:1591-97.

${ }^{50}$ Rivera GA, David IB, Anand RG. Successful Atrioesophageal Fistula Repair After Atrial Fibrillation Ablation. Images in Cardiology. JACC. 2013;61(11).

${ }^{51}$ Tancevski I, Hintringer F, Stuehlinger M. Atrioesophageal Fistula After Percutaneous Transcatheter Ablation of Atrial Fibrillation. Images in Cardiovascular Medicine. Circulation. 2012;125:966.

${ }^{52}$ Starek Z, et al. Long-term mobility of the esophagus in patients undergoing catheter ablation of atrial fibrillation: data from computer tomography and 3D rotational angiography of the left atrium. J Interv Card Electrophysiol. 2016;46(2):81-7.

${ }^{53}$ Daoud EG, et al. Comparison of computed tomography imaging with intraprocedural contrast esophagram: implications for catheter ablation of atrial fibrillation. Heart Rhythm. 2008;5:975980.

${ }^{54}$ Good E, et al. Movement of the esophagus during left atrial catheter ablation for atrial fibrillation. J Am Coll Cardiol. 2005;46:2107-2110.

${ }^{55}$ Starek Z, et al. Esophageal positions relative to the left atrium; data from 293 patients before catheter ablation of atrial fibrillation. Indian Heart Journal. 2018;70:37-44.

56 Bunch TJ, May HT, Crandall BG. Intracardiac Ultrasound for Esophageal Anatomic Assessment and Localization During Left Atrial Ablation for Atrial Fibrillation. J Cardiovasc Electrophysiol. 2013;24:33-39.

${ }^{57}$ Lemola K, et al. Computed tomographic analysis of the anatomy of the left atrium and the esophagus: Implications for left atrial catheter ablation. Circulation 2004;110:3655-3660.

${ }^{58}$ Singh S, et al. Esophageal injury and temperature monitoring during atrial fibrillation ablation. Circ Arrhythm Electrophysiol. 2008;1:162-168.

${ }^{59}$ Halm U, et al. Thermal esophageal lesions after radiofrequency catheter ablation of left atrial arrhythmias. Am J Gastroenterol. 2010;105:551-556.

${ }^{60}$ Sause A, et al. Limiting esophageal temperature in radiofrequency ablation of left atrial tachyarrhythmias results in low incidence of thermal esophageal lesions. BMC Cardiovascular Disorders. 2010;10:52. 
${ }^{61}$ Sternick EB, Persiano AC, Arantes V. Is it safe to monitor esophageal temperature during AF ablation? Europace. 2012;14:1432.

${ }^{62}$ Müller P, et al. Higher incidence of esophageal lesions after ablation of atrial fibrillation related to the use of esophageal temperature probes. Heart Rhythm. 2015;12:1464-1469.

${ }^{63}$ Halbfass P, et al. Incidence of asymptomatic oesophageal lesions after atrial fibrillation ablation using an oesophageal temperature probe with insulated thermocouples: a comparative controlled study. Europace. 2017;19(3):385-391.

64 Arruda MS. Pre-clinical "in vivo" evaluation of an esophageal protective system: Implications on esophageal thermal injury during AF ablation. Heart Rhythm. 2008;5:S16.

${ }^{65}$ Kuwahara T, Takahashi A, Okubo K. Oesophageal cooling with ice water does not reduce the incidence of oesophageal lesions complicating catheter ablation of atrial fibrillation: randomized controlled study. Europace. 2014;16(6):834-9.

${ }^{66}$ Mateos JC, Mateo EI, Peña TG, et al. Simplified method for esophagus protection during radiofrequency catheter ablation of atrial fibrillation - prospective study of 704 cases. Rev Bras Cir Cardiovasc. 2015;30(2):139-47.

${ }^{67}$ Chugh A, Rubeinstein J, Good E. Mechanical displacement of the esophagus in patients undergoing left atrial ablation of atrial fibrillation. Heart Rhythm. 2009;6:319-322.

${ }^{68}$ Koruth JS, et al. Mechanical Esophageal Displacement During Catheter Ablation for Atrial Fibrillation. J Cardiovasc Electrophysiol. 2012; 23:147-154.

${ }^{69}$ Bhardwaj R, et al. Esophageal Deviation During Atrial Fibrillation Ablation: Clinical Experience With a Dedicated Esophageal Balloon Retractor. JACC Clin Electrophysiol. 2018;4(8):1020-1030.

${ }^{70}$ Cummings JE, et al. Assessment of Temperature, Proximity, and Course of the Esophagus During Radiofrequency Ablation Within the Left Atrium. Circulation. 2005;112:459-464.

${ }^{71}$ Magalhães LP, et al. II Diretrizes Brasileiras de Fibrilação Atrial. Arq Bras Cardiol. 2016;106(2):1-22.

${ }^{72}$ Mathur SK, Singh P. Transoesophageal echocardiography related complications. Indian J Anaesth. 2009;53(5):567-74.

${ }^{73}$ Pappone C, et al. Atrio-esophageal fistula as a complication of percutaneous transcatheter ablation of atrial fibrillation. Circulation. 2004;109(22):2724-6.

${ }^{74}$ Scanavacca MI, et al. Left atrial-esophageal fistula following radiofrequency catheter ablation of atrial fibrillation. J Cardiov Electrophysiol. 2004;15(8):960-2.

${ }^{75}$ WG Daniel, R Erbel, W Kasper. Safety of transesophageal echocardiography. A multicenter survey of 10,419 examinations. Circulation. 1991;83;817-821.

${ }^{76}$ Urbanowicz JH, Kernoff RS, Oppenheim, Gary. Transesophageal Echocardiography and Its Potential for Esophageal Damage. Anesthesiology. 1990;72:40-43.

${ }^{77}$ Calkins H, et al. HRS/EHRA/ECAS/APHRS/SOLAECE expert consensus statement on catheter and surgical ablation of atrial fibrillation: executive summary. J Interv Card Electrophysiol. 2017 Oct;50(1):1-55.

${ }^{78}$ Pérez JJ, et al. Electrical and Thermal Effects of Esophageal Temperature Probes on Radiofrequency Catheter Ablation of Atrial Fibrillation: Results from a Computational Modeling Study. J Cardiovasc Electrophysiol. 2015;26:556-564. 